\title{
Systematic Review Systematic Literature Review of Realistic Simulators Applied in
Educational Robotics Context
}

\author{
Caio Camargo ${ }^{1}$, José Gonçalves ${ }^{1,2,3} \mathbb{0}$, Miguel Á. Conde ${ }^{4, *} \mathbb{0}$, Francisco J. Rodríguez-Sedano ${ }^{4}$, Paulo Costa ${ }^{3,5}$ and \\ Francisco J. García-Peñalvo ${ }^{6}$ (D) \\ 1 Instituto Politécnico de Bragança, 5300-253 Bragança, Portugal; caioo.rafael@gmail.com (C.C.); \\ goncalves@ipb.pt (J.G.) \\ 2 CeDRI-Research Centre in Digitalization and Intelligent Robotics, 5300-253 Bragança, Portugal \\ 3 INESC TEC-Institute for Systems and Computer Engineering, 4200-465 Porto, Portugal; paco@fe.up.pt \\ 4 Robotics Group, Engineering School, University of León, Campus de Vegazana s/n, 24071 León, Spain; \\ francisco.sedano@unileon.es \\ 5 Universidade do Porto, 4200-465 Porto, Portugal \\ 6 GRIAL Research Group, Computer Science Department, University of Salamanca, 37008 Salamanca, Spain; \\ fgarcia@usal.es \\ * Correspondence: mcong@unileon.es
}

Citation: Camargo, C.; Gonçalves, J.; Conde, M.Á.; Rodríguez-Sedano, F.J.; Costa, P.; García-Peñalvo, F.J. Systematic Literature Review of Realistic Simulators Applied in Educational Robotics Context. Sensors 2021, 21, 4031. https://doi.org/ $10.3390 / \mathrm{s} 21124031$

Academic Editor: Seokheun Choi

Received: 5 May 2021

Accepted: 4 June 2021

Published: 11 June 2021

Publisher's Note: MDPI stays neutral with regard to jurisdictional claims in published maps and institutional affiliations.

Copyright: (c) 2021 by the authors. Licensee MDPI, Basel, Switzerland. This article is an open access article distributed under the terms and conditions of the Creative Commons Attribution (CC BY) license (https:// creativecommons.org/licenses/by/ $4.0 /)$.

\begin{abstract}
This paper presents a systematic literature review (SLR) about realistic simulators that can be applied in an educational robotics context. These simulators must include the simulation of actuators and sensors, the ability to simulate robots and their environment. During this systematic review of the literature, 559 articles were extracted from six different databases using the Population, Intervention, Comparison, Outcomes, Context (PICOC) method. After the selection process, 50 selected articles were included in this review. Several simulators were found and their features were also analyzed. As a result of this process, four realistic simulators were applied in the review's referred context for two main reasons. The first reason is that these simulators have high fidelity in the robots' visual modeling due to the $3 \mathrm{D}$ rendering engines and the second reason is because they apply physics engines, allowing the robot's interaction with the environment.
\end{abstract}

Keywords: robotics; education; realistic simulators; sensors; actuators; physics engine

\section{Introduction}

With the development of computers, simulation has become a powerful tool in the many areas in which it can support design, planning, analysis and decision-making in research and development [1-5].

Simulation is the process of designing a model of an actual or theoretical physical system, executing the model and analyzing the output. It helps to understand our reality and its complexity by building artificial objects and dynamically acting out roles. The simulation application enables learning about something in a very effective way and, by modifying environment rules, we can observe the results of the interactions. It is also an interdisciplinary field, applied in all research fields in society, from engineering and computer science to economics and social science, and at all different scientific study levels, even to manufacturers. Researchers and companies may build experimental systems using simulators even in the early development stages, testing complexity, reality and specificity. The simulation tests can be gradually increased to a level where these virtual systems can help to solve real challenges of the physical world, create new revolutionary products and push human imagination and creative boundaries-one of the main applications of simulation in the robotics field. By designing new products and investigating performance, simulation permits the study of structures, characteristics and a robotic system's function no matter how complex it is. Although, as the system's complexity increases, the need for simulation rises at the same level. Hence, the simulation tools can, for sure, improve 
design, development and robotic operating systems. Simulators utilizing a graphical user interface and visualization tools can provide us with a realistic way of visualizing the robotics system's operation [1].

Robot simulation started to become feasible and got more attention when the computational power of personal computers increased over the years in a significant way. In almost every computer today, it is possible to run complex algorithms and many graphical calculations. With that, realistic simulations are also possible thanks to the game industry's efforts to create realistic visualisation in computer games. The creation of virtual worlds requires considerable processing power to render graphical environments and physics calculations. Consequently, this effort developed software engines that provide high-quality physics simulations and rendering software in the robotics domain [2].

In this context, physics engines are software that allow computers to create physics phenomena that we experience in the real world, that is, rigid body dynamics, collision detection, soft body dynamics, fluid dynamics and other physical aspects, and apply them to 3D objects in games (the most usual application) and other 3D renderings, which affects how those objects interact in the digital world. Game developers and video effects artists use physics engines to create lifelike computer-generated environments for video games, movies and television. Some architects may use physics engines to create realistic $3 \mathrm{D}$ renderings for concept designs. Even if a 3D environment does not require reallife physics, a physics engine will allow the designer to customise physics to fit their needs $[6,7]$.Without something like a physics engine telling many different $3 \mathrm{D}$ objects how to interact, programming an environment would be extremely time-consuming. Some environments may have hundreds of objects that all interact with each other in various ways. For example, an object in a bowl on a table is interacting with the bowl, the other objects in the bowl, the table and the ground the table sits on. As a game developer or video effects artist, a physics engine will be part of the suite of tools applied to create 3D environments. In many cases, physics engines are included in game engines, 3D modeling suites and 3D rendering tools. However, it may be offered as a standalone or as a plug-in to another software $[8,9]$.

To qualify as a physics engine, a software must:

1. Simulate a variety of physical systems (rigid body dynamics, soft body dynamics, fluid dynamics, etc.);

2. Apply those systems to 3D objects and environments;

3. Work in tandem with other software systems to create a cohesive experience.

The main objective of this work is to present a systematic literature review that allows us to understand whether there are any realistic simulators that are or can be applied in an educational robotics context, and to obtain scientific databases in order to analyze and compare the features of these kinds of simulators. The reason for exploring the educational context is because of the multiple advantages for pre-university students of robotics application [10], specially for developing STEAM related competences [11]. Still within the context of educational robotics, this research seeks to find, analyze and compare realistic simulators capable of simulating robots, sensors and actuators in general. In order to answer the research question of this work and fulfill the goal, this review becomes important for future applications and frameworks that can be developed using these simulation tools to be applied at all educational levels and, as a consequence, in teaching robotics and computer science topics.

The structure of this work is as follows: Section 2 describes all the methodology followed to execute the systematic literature review [12], the research question, the PICOC method and the search string equation that was applied to the databases. Section 3 presents a Preferred Reporting Items for Systematic Reviews and Meta-Analyses (PRISMA) flow diagram with all the papers obtained from the database searches of the previous section. Section 4 discusses and analyzes the results from the selected and relevant papers, after filtering by selection criteria. Finally, in Section 5, conclusions and future work are proposed. 


\section{Method}

This paper was conducted by following the systematic literature review methodology presented by Kitchenham [13-15]. A systematic literature review is a means of evaluating and interpreting all available research, relevant to a particular research question, topic area, or phenomenon of interest. The SLR aims to present a fair evaluation of a research topic using a trustworthy, rigorous and auditable methodology. The guidelines for conducting an SLR are divided into three phases: planning the review, conducting the review and reporting the review [16-22].

Before starting the planning of the SLR, a preliminary search is needed on a database, such as Google Scholar, to verify if there is an SLR with the same theme of research. If there is an SLR with the same topic, there would not be any need to conduct a new one $[23,24]$. In the case of this systematic review of the literature, no results were found, covering the realistic simulators subject, therefore, the SLR can be carried out as new research.

\subsection{Planning the Review}

The first part is the review planning, consisting of the process of identification and definition of the review execution, ensuring that the review is traceable [25]. At the beginning, it is necessary to clearly specify the research question that it aims to investigate. For this work, taking into account the described context in the Introduction, the research questions (RQs) are:

- $\quad$ RQ1: In the context of educational robotics, are there any realistic simulators capable of simulating any robot prototype?

- RQ2: Are these simulators capable of simulating the robot's sensors and/or actuators?

- RQ3: Is such simulation based on physics engines?

Once the research questions have been defined, the PICOC method proposed by Petticrew and Roberts [22] was followed to define the review scope.

- Population (P): Robotics Simulators;

- Intervention (I): Realistic Robotics Simulators;

- Comparison (C): Compare the already existing robotics simulators;

- $\quad$ Outcome (O): Understand the ways of simulate realistic robots, being able to simulate micro-controllers, sensors and actuators as well;

- Context (C): Educational Robotics.

\subsection{Inclusion and Exclusion Criteria}

With the PICOC established, the scope of the review has been set, accompanied by the research questions and selection criteria-inclusion (IC) and exclusion (EC) — are defined to select the relevant papers that answer the research questions. For a paper to be selected, it has to meet all the Inclusion Criteria, and if it meets any Exclusion Criteria, it will be excluded.

- IC1: The papers are written in English; (AND)

- IC2: The papers are reported in peer reviewed conferences or journals or technical reports; (AND)

- IC3: The papers that use any kind of simulator, OR simulate realistic robotics, OR simulate sensors OR Actuators.

The Exclusion Criteria are the opposite of the Inclusion Criteria.

- $\quad$ EC1: The papers are NOT written in English; (OR)

- $\quad$ EC2: The papers are NOT reported in peer reviewed conferences or journals or technical reports; (OR)

- EC3: The papers that do NOT use any kind of simulator, OR simulate realistic robotics, OR simulate sensors OR Actuators. 
These selection criteria will determine whether, from reading the paper's title and abstract, it will be included in the review or not, and whether it is useful to include relevant works in the review in terms of its scope.

\subsection{Search Methodology}

The methodology of an SLR differs from a search made randomly on the Internet in several aspects. One of the most relevant is the need to determine the data sources, which should be the most important databases in terms of the research context. The electronic databases used in this work were: ACM Digital Library, IEEE Digital Library, ISI Web of Science, ScienceDirect, Scopus and Springer Link.

These databases were selected for three main reasons:

1. They are well-known databases in this research field;

2. They are relevant databases in the research theme of this literature review;

3. It is possible to use a search string as well as Boolean operators to improve the results of the search process.

Given this procedure, the next step is to define the search string equation for the different databases. It was built using relevant terms from the PICOC methodology and they were connected by Boolean "AND" and "OR" operators [26,27]. Moreover, the asterisk sign operator was used to include both the singular and plural of each term. Taking this into account, the search string equation is shown as follows:

("educational robotics" OR "educative robotics" OR "robotics and education") AND ("realistic simulators" OR "prototype" OR "prototyping")

The search string equation is divided into two main parts. The first part contains three related concepts, which are: "Educational Robotics", "Educative Robotics" or "Robotics and Education". These concepts are inclusive and connected between each other, and they were retrieved from the Context from the PICOC methodology. The search string equation will be executed in the all electronic databases in order to gather all the published papers connected with those areas.

The second part of the search equation is related to the main objective of this work, the terms: "Realistic Simulators", "Prototype" or "Prototyping". The "Realistic Simulators" term has the role of finding in the electronic databases all the papers that in some way have used a realistic simulator. The two last terms "Prototype" or "Prototyping" are related and help to expand our search, because these words represent one of the main applications for simulators, that is, prototype simulation.

The following describes and shows the search strings equation applied to each database.

1. ACM Digital Library: For the ACM Digital Library (http:/ / portal.acm.org, accessed on 8 June 2021) the Advanced Search resource was used, where the search equation was split into two parts placed in two separated search fields; the query syntax returned from this database is is shown below:

[[All: "educational robotics"] OR [All: "educative robotics"] OR [All: "robotics and education"]] AND [[All: "realistic simulators"] OR [All: "prototype"] OR [All: "prototyping"]]

2. IEEE Digital Library: In the IEEE Digital Library (http:/ / ieeexplore.ieee.org, accessed on 8 June 2021), we used the simple search bar on the web site, pasting the search strings there.

3. ISI Web of Science: In the ISI Web of Science (http://www.isiknowledge.com, accessed on 8 June 2021) he query terms were posted in the basic search tab to obtain the papers.

4. ScienceDirect: For ScienceDirect (http://www.sciencedirect.com, accessed on 8 June 2021), the use of the website was very straight forward; the equation was pasted in the search field to obtain the results from the database. 
5. Scopus: In the Scopus database (http:/ / www.scopus.com, accessed on 8 June 2021), the use of advanced search was needed in order to obtain the maximum possible results. The entered query strings used were:

\section{ALL("Educational Robotics" OR "Educative Robotics" OR “Robotics and Education") AND ALL("Realistic Simulators" OR "Prototype" OR “Proto- typing").}

6. Springer Link: For the Springer Link database (http:/ /link.springer.com, accessed on 8 June 2021), the query string was used in the simple search bar on the website.

\subsection{Quality Criteria}

After the first preliminary part of paper selection, described as the Inclusion and Exclusion criteria, a new set of questions was defined to check the work's quality before including them in the final literature review.

Each question can be answered with a possible weight between three values: 4.0 (Yes, it answers the question fully), 2.0 (Yes, it answers the question partially) and 0.0 (No, it does not answer the question). These values are assigned to the papers by reading them fully. The quality assessment checklist is shown in Table 1.

Table 1. Quality Assessment Checklist.

\begin{tabular}{cc}
\hline Quality Questions & Questions \\
\hline QQ1 & Is the paper based on research or is it a report based on expert opinion? \\
QQ2 & Is there a description of the context in which the research was carried out? \\
QQ3 & Is there a clear statement of the aims of the research? \\
QQ5 & Was the research conducted to address the aims of the research? \\
QQ6 & Were the simulations made during the study applied in an educational context? \\
QQ7 & Could the simulator used in the study be applied in an educational context? \\
QQ8 & Is the simulator used in the research able to make realistic simulations? \\
QQ9 & Was the method used during the study described? \\
QQ10 & Was the data analysis sufficiently rigorous? \\
QQ11 & Is the study of value for the research field? \\
\hline
\end{tabular}

Therefore, each paper can be assigned a maximum of 44.0 points based on the quality criteria. In Figure 1, it can be observed the distribution of these quality data.

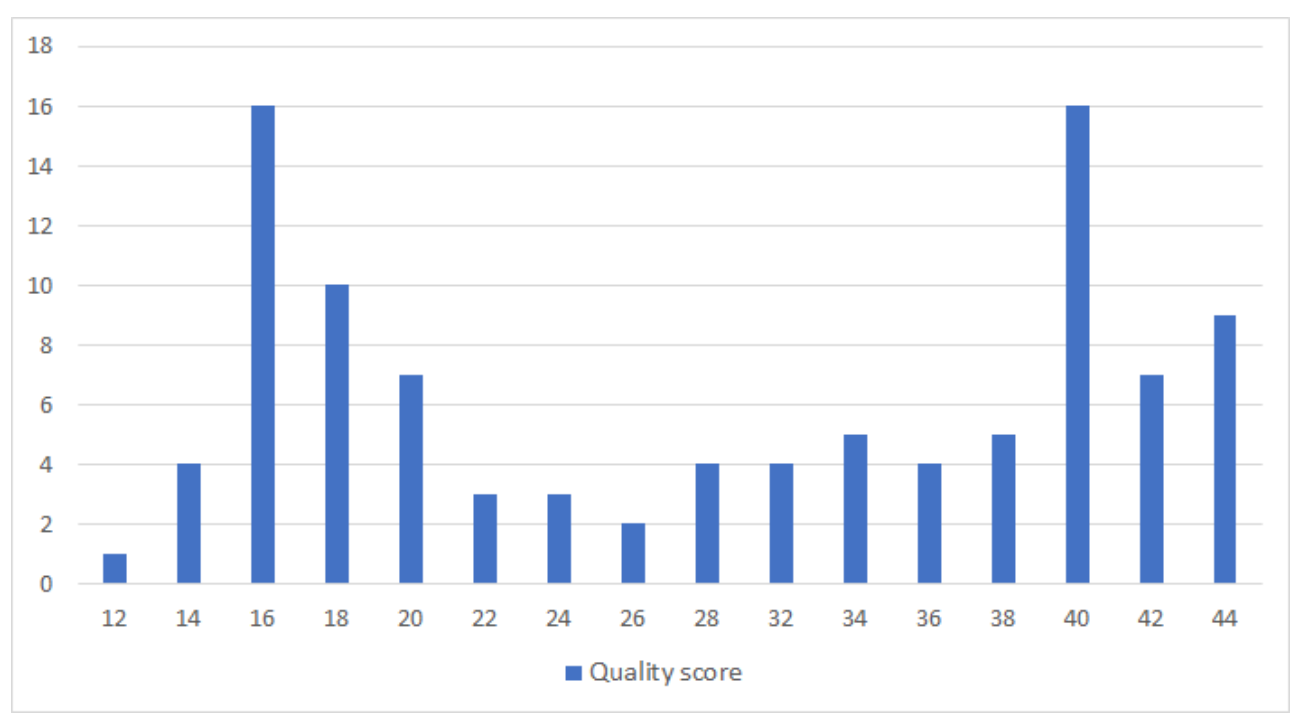

Figure 1. Distribution of Quality Data. 
The median overall score (out of 44 ) of the 100 included studies was 30 , and the mean overall score was 29.08. We, therefore, decided to set a cut-off score of 30 points. All those papers that exceeded this score were included in the final synthesis.

\section{Data Extraction Form}

When the quality assessment process of the papers was running out, a data extraction form was made with a set of questions to evaluate the simulators used during the reading of the works. These questions are shown in Table 2.

Table 2. Data Extraction Form.

\begin{tabular}{cc}
\hline Data Questions & Questions \\
\hline DQ1 & Is the simulator able to simulate robotics? \\
DQ2 & Is the simulator able to simulate sensors? \\
DQ3 & Is the simulator able to simulate actuators? \\
DQ4 & What method is used for the simulator? \\
DQ5 & Is the realistic simulation made under a mathematical-physical model? \\
DQ6 & What is the simulator used? \\
DQ7 & Is the simulator free to use? \\
DQ8 & Is the simulator open-source or not? \\
\hline
\end{tabular}

For the first three questions (DQ1, DQ2 and DQ3), the answer is Boolean so it could be answered with "Yes" or "No". The following three questions (DQ4, DQ5 and DQ6) should be answered with strings. DQ4 describes the method used in the paper for using the simulator; DQ5 describes whether the simulation was made under a mathematicalphysical model; and DQ6 states the name of the simulator applied. The last two questions required selecting one possible option. DQ7 asks if the simulator is free to use, is fully paid or a mix of both and DQ8 asks if the simulator is an open-source platform or not. The result of this data extraction will be presented in the results section in a Table format, in which every mentioned simulator in the papers has a score equal to or above 30.0.

\section{Results}

This section presents all the results obtained from the searches on the databases. The data compilation was divided into different phases according to the PRISMA flow diagram, shown in Figure 2, which details the actions taken during the SLR process [28,29].

This process was carried out following the methodology described in Section 2.3. The search on the databases was performed (on 27 August 2020), carrying on with the paper selection process:

1. First, the results retrieved from the initial search were 559 papers in total, distributed in 41 citations from the ACM Digital Library, 14 from the IEEE Digital Library, 22 papers from ISI Web of Science, 92 works from ScienceDirect, 204 citations from Scopus and 186 from Springer Link.

2. After the search, all these references were uploaded and organized into the Parsifal (https: / / parsif.al/, accessed on 8 June 2021) (the main tool applied to conduct this SLR) and it detected 60 duplicated records that were consequently removed.

3. As result, 499 works were retrieved from the previous step and they were analyzed through the reading of their titles, keywords and abstracts and applying the Inclusion and Exclusion Criteria. From this process, 434 articles were excluded because they did not meet the requirements, leading us to the next phase, with 65 papers.

4. The accepted papers were read in detail. When each article was read, it was scored regarding its quality, applying the quality assessment questions described in Section 2.4. In addition, while reading these works, their references were carefully checked in order to find new articles (as an alternative source) that could address the research question, resulting in 35 new reports (on 7 December 2020). Figure 3 shows the amount of obtained articles per source and year, and those which were accepted per source. 
A relevant issue to take into account is that none of the selected papers were from the Web of Science or the IEEE Digital library data sources, so these databases are not shown in the graphic.

5. After the evaluation of the papers' quality, 15 papers that scored higher than or equal to 30 were selected, adding to them the 35 obtained from the reference checking of the previous phase. This resulted in a total of 50 selected works with which to compose the present review, which can be seen distributed by publication year and source in the Figure.

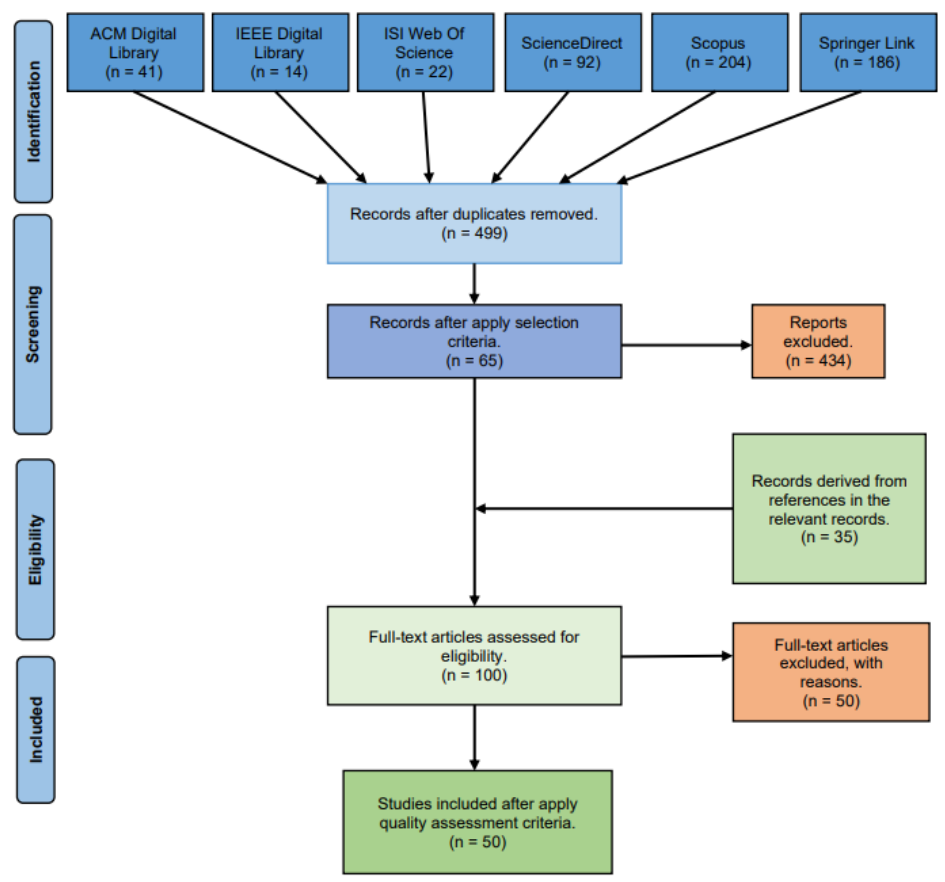

Figure 2. The Systematic Literature Review process. Adapted from [29].

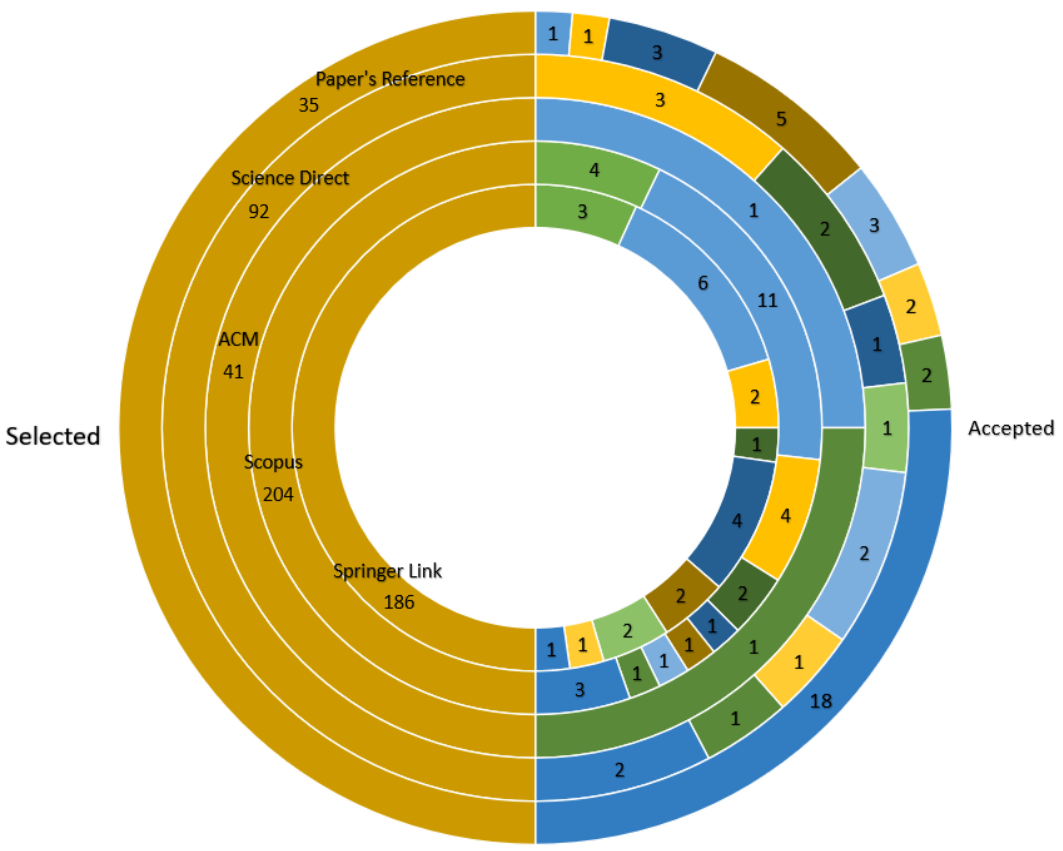

|| 2020 | 2019 || 2018 | 2017 | 2016 | 2015 || 2014||$-2013$ || 2012 || 2011 || 2010 and Before || Selected

Figure 3. Distribution of publication per year and source. 


\section{Discussion and Results}

This section describes the results of the developed systematic literature review. How every simulator addresses the research questions (RQ1, RQ2 and RQ3) made in the Section 2.1 is discussed, through the data extraction form presented in Table 2. Taking this into account, further subsections point out the answers to the data questions by discussing three main issues: (1) the features of the simulators found in the review; (2) some interesting exceptions about papers included in the study; and (3) the features of the engines, on which the simulators are based. Finally, a subsection describes the Robot Operating System, which is an alternative method for writing the robots' software in the simulators.

Table 3 presents all the papers selected, showing their quality scores, the name of the simulator used and its ability to simulate robots, and its sensors and actuators. Note that the columns tagged as $\mathbf{d}, \mathbf{e}$ and $\mathbf{f}$ address the answers to Data Questions 1, 2 and 3, meaning whether the simulator is able to simulate robotics, sensors and actuators, respectively.

Table 3. All the papers included in the SLR. In $\left({ }^{a}\right)$ All the selected studies about simulators. $\left({ }^{b}\right)$ The answer for Data Question 6 (DQ6), in which the answer is the name of the simulator used in the refereed study. The $\left({ }^{\mathrm{C}}\right)$ column is the paper's score in the quality assessment. Lastly, $\left({ }^{\mathrm{d}}\right),\left({ }^{\mathrm{e}}\right)$ and $\left({ }^{\mathrm{f}}\right)$ columns concern the ability to simulate robotics, sensors and actuators, addressing Data Questions (DQ1),(DQ2) and (DQ3), respectively.

\begin{tabular}{|c|c|c|c|c|c|}
\hline Reference $^{a}$ & DQ6 $^{b}$ & Score $^{c}$ & DQ1 ${ }^{d}$ & $\mathrm{DQ2}^{\mathrm{e}}$ & $\mathrm{DQ}^{\mathrm{f}}$ \\
\hline [30] & ARGoS & 40 & True & True & True \\
\hline [31] & Sim-Two & 36 & True & True & True \\
\hline [32] & Sim-Two & 40 & True & True & True \\
\hline [33] & Sim-Two & 40 & True & True & True \\
\hline [34] & Sim-Two & 38 & True & True & True \\
\hline [35] & ROS & 34 & False & False & False \\
\hline [36] & Gazebo & 40 & True & True & True \\
\hline [37] & RoSoS & 44 & True & False & False \\
\hline [38] & Sim-Two & 44 & True & True & True \\
\hline [39] & USARSim & 38 & True & True & True \\
\hline [40] & Breve & 34 & True & False & False \\
\hline [41] & Sim-Two & 40 & True & True & True \\
\hline [42] & Sim-Two & 40 & True & True & True \\
\hline [43] & V-REP & 44 & True & True & True \\
\hline [44] & ROS Development Studio & 36 & True & True & True \\
\hline [45] & Gazebo & 40 & True & True & True \\
\hline [46] & Webots & 32 & True & True & True \\
\hline [47] & Gazebo & 36 & True & True & True \\
\hline [48] & Simulink & 34 & False & True & True \\
\hline [49] & V-REP & 44 & True & True & True \\
\hline [50] & Gazebo & 42 & True & True & True \\
\hline [51] & Sim-Two & 40 & True & True & True \\
\hline [52] & Sim-Two & 38 & True & True & True \\
\hline [53] & Gazebo & 36 & True & True & True \\
\hline [54] & Sim-Two & 40 & True & True & True \\
\hline [55] & Sim-Two & 40 & True & True & True \\
\hline [56] & Sim-Two & 40 & True & True & True \\
\hline [57] & Player/Stage & 42 & True & True & True \\
\hline [58] & jmeSim & 32 & True & True & True \\
\hline [59] & Sim-Two & 44 & True & True & True \\
\hline [60] & Stage & 40 & True & True & True \\
\hline [61] & Exception 1 & 34 & True & True & True \\
\hline [62] & Sim-Two & 44 & True & True & True \\
\hline [63] & Sim-Two & 40 & True & True & True \\
\hline
\end{tabular}


Table 3. Cont.

\begin{tabular}{cccccc}
\hline Reference $^{\mathbf{a}}$ & DQ6 $^{\mathbf{b}}$ & Score $^{\mathbf{c}}$ & DQ1 $^{\mathbf{d}}$ & DQ2 $^{\mathbf{e}}$ & DQ3 $^{\mathbf{f}}$ \\
\hline$[64]$ & Sim-Two & 40 & True & True & True \\
{$[65]$} & Sim-Two & 32 & True & True & True \\
{$[66]$} & Gazebo & 42 & True & True & True \\
{$[67]$} & Sim-Two & 44 & True & True & True \\
{$[68]$} & UberSim & 38 & True & True & True \\
{$[69]$} & Sim-Two & 44 & True & True & True \\
{$[70]$} & Creo & 32 & True & True & True \\
{$[71]$} & Sim-Two & 42 & True & True & True \\
{$[72]$} & Sim-Two & 38 & True & True & True \\
{$[73]$} & Sim-Two & 40 & True & True & True \\
{$[74]$} & Gazebo & 42 & True & True & True \\
{$[1]$} & MATLAB/Simulink & 42 & True & True & True \\
{$[75]$} & Exception 2 & 42 & True & True & True \\
{$[76]$} & UberSim & 40 & True & True & True \\
{$[77]$} & V-REP & 34 & True & True & True \\
{$[78]$} & V-REP & 44 & True & True & True \\
\hline
\end{tabular}

As shown in Table 3, several simulators were found, and the most used from the selected papers were Sim-Two (22 times), Gazebo (7 times) and V-REP (4 times). Something to point out is that the papers with a score of 42 points or 44 points are those applied in the educational context that were able to simulate all the features inquired for the research questions, but with a few exceptions (such as Exception 1 and Exception 2) that are described in the next subsections.

Although the most used simulators were Sim-Two, Gazebo and V-REP, others were found through the reading process (Table 3 ). The table presents a distribution of the simulators in this literature review.

As can be noticed, the most mentioned simulators found in the full-read process were: USARSim, Gazebo, Webots, Sim-Two, Stage/Player, V-REP, UberSim, MuRoSimF and the Microsoft Robotics Studio. To better understand the reason why the papers' authors cite or use them, each simulator is investigated and described in the next subsection.

\subsection{Simulators Features}

In this subsection the features of the simulators found in the literature are described. Besides the papers studied during the research methodology, in this part it another search was made in Google Scholar in order to find papers that contain the simulators' details and facts to add and support the information about the simulators presented in Table 4 . This is necessary because, as the analysis in Figure 3 shows, most of the papers included are from before 2016, and many of the features of the simulators may have changed through the years due to technology evolution. The simulator features can be found in Table 5 .

As can be observed, many simulators were found during the search. The main characteristic among some of them is that they are based on physics engines, which allows them to simulate the robot and the robot's environment in a more realistic way. Another important feature that was noticed was that some of these simulators are defined with multiple simulation purposes (ie V-REP, Webots, Gazebo, SimTwo and others), which means they are able to simulate several types of robots, unlike others that only simulate one type of robot (i.e., ARGoS, RoSoS, UberSim, OpenHRP3, Khepera and others). 
Table 4. All the simulators mentioned throughout the full-read papers.

\begin{tabular}{cc}
\hline Simulators & Found in \\
\hline USARSim & {$[30,36,39,60,75]$} \\
SimSpark & {$[32-34]$} \\
ROS Development Studio & {$[44]$} \\
Gazebo & {$[30,36,38,39,43-45,47,49,50,53,57,60,66,74,75,77]$} \\
Webots & {$[30,32-34,36,39,43,44,46,49,57,60,75,77]$} \\
Sim-Two & {$[31-33,38,41,42,51,52,54-56,59,62,64,65,67,69,72,73]$} \\
ARGoS & {$[30,49,60]$} \\
Stage/Player & {$[38,39,57,60]$} \\
MORSE & {$[57]$} \\
STDR & {$[57]$} \\
V-REP & {$[36,43,49,57,77,78]$} \\
RoSoS & {$[37]$} \\
UberSim & {$[32-34,67,76]$} \\
Breve & {$[40]$} \\
Teambots & {$[60]$} \\
MuRoSimF & {$[30,32-34]$} \\
OpenHRP3 & {$[32,33,36,60]$} \\
jmeSim & {$[33,77]$} \\
BOB & {$[36,58]$} \\
Khepera & {$[38]$} \\
Delta3D & {$[38]$} \\
MATLAB/Simulink & {$[38]$} \\
Swarmbot3d & {$[1,48]$} \\
Creo & {$[60]$} \\
& {$[70]$} \\
\hline Roft &
\end{tabular}

As a result of searching information about the simulators listed above, an Excel file was uploaded into a GitHub repository, a summarized Table showing only the simulator's main features. The repository's link can be found in Appendix A.

Finally, most of the simulators were developed in the $2000 \mathrm{~s}$, and it can be observed that the most mentioned simulators in Table 5 still continue to have updates for current technologies since their launch. An exception to these simulators is the Microsoft Robotics Studio, which has been discontinued, as have UberSim and Khepera.

Table 5. Simulators Features.

\begin{tabular}{|c|c|c|c|}
\hline \multicolumn{4}{|c|}{ Simulators } \\
\hline \multirow{7}{*}{ USARSim } & Description & $\begin{array}{l}\text { Unified System for Automation } \\
\text { is a high-fidelity simulation of ro } \\
\text { game engine. It was built upon } \\
\text { produced by Epic Games. It has } \\
\text { models, and physics-based sin } \\
\text { classes that define the simulati } \\
\text { simulate several types of robots }\end{array}$ & $\begin{array}{l}\text { Simulator, forming the acronym USARSim, } \\
\text { avironments based on the Unreal Tournament } \\
\text { ine } 2.0 \text {, a game engine commercially available } \\
\text { applications programmer interface, validated } \\
\text { SARSim is composed of a set of models and } \\
\text { s, sensors and actuators. It has the ability to } \\
\text { robots, underwater vehicles, legged platforms } \\
\text { hoids }[39,79] \text {. }\end{array}$ \\
\hline & \multirow{6}{*}{ Features } & Robot Types & Wheeled; Underwater; Legged Humanoids; \\
\hline & & Sensors and Actuators & $\begin{array}{c}\text { Odometry; INU; Encoder; Touch; Range(Sonar, } \\
\text { IR, Scanner); RFID Robot Camera Sound } \\
\text { HumanMotion }\end{array}$ \\
\hline & & Compatibility & Player MOAST \\
\hline & & Engines & Unreal Engine \\
\hline & & $\begin{array}{l}\text { Programming } \\
\text { Languages }\end{array}$ & UnrealScript \\
\hline & & Other Features & $\begin{array}{c}\text { Users can add new robots models, sensors and } \\
\text { actuators; 3D Visualization; Open-Source; Free } \\
\text { to Use; }\end{array}$ \\
\hline
\end{tabular}


Table 5. Cont.

\section{Simulators}

The SimSpark is a multi-robot simulator based on the generic components of the Spark physical multi-agent simulation system and its main application is in the Soccer

Competitions. This simulator is implemented through the Open Dynamics Engine (ODE)

Description for physically realistic dynamics simulation, allowing fast rigid body simulations, collision detection and the use of articulated body structures. It also includes a 3D visualization based on OpenGL, enabling the possibility to create scenes. The creation of new robot models it is possible using the Ruby interface in which is an interpreted language [32-34,80,81].

SimSpark

\begin{tabular}{cc} 
Robot Types & Wheeled; Legged; Humanoids; \\
\hline Sensors and Actuators & Gyroscope; Motors; \\
\hline Compatibility & TCP Protocol; UDP Protocol; \\
\hline Engines & ODE OpenGL \\
\hline Programming Languages & C++ Ruby \\
\hline
\end{tabular}

Other Features

Users can add new robots models, sensors and actuators; 3D Visualization; Open-Source; Free to Use;

\begin{tabular}{|c|c|c|c|}
\hline \multirow{7}{*}{$\begin{array}{l}\text { ROS } \\
\text { Development } \\
\text { Studio }\end{array}$} & \multirow[t]{2}{*}{ Description } & \multicolumn{2}{|c|}{$\begin{array}{l}\text { ROS Development Studio is a web application for the simulation of robots in the cloud. } \\
\text { This platform consists of virtual machines running in the could infrastructure provided } \\
\text { by Amazon Web Services. The cloud platform supports two simulators, which are } \\
\text { Gazebo and Webots [44]. }\end{array}$} \\
\hline & & Robot Types & Not Applicable \\
\hline & \multirow{5}{*}{ Features } & $\begin{array}{l}\text { Sensors } \\
\text { and } \\
\text { Actuators }\end{array}$ & Not Applicable \\
\hline & & Compatibility & Not Applicable \\
\hline & & Engines & Not Applicable \\
\hline & & $\begin{array}{l}\text { Programming } \\
\text { Languages }\end{array}$ & Not Applicable \\
\hline & & Other Features & Not Applicable \\
\hline \multirow{7}{*}{ Gazebo } & Description & $\begin{array}{l}\text { Gazebo simulator came up as a } \\
\text { accurately reproduce the dy } \\
\text { open source and freely availab } \\
\text { and its major feature is the abilit } \\
\text { It was built based on the Op } \\
\text { DART physics engines. The vis } \\
\text { OpenGL and GLUT (OpenGL }\end{array}$ & $\begin{array}{l}\text { the Player and Stage project, and was designed to } \\
\text { nts that a robot may encounter. It is completely } \\
\text { ables the support to simulate multi robot systems, } \\
\text { new robots, actuators, sensors and arbitrary objects. } \\
\text { ne, and currently supports Bullet, Simbody and } \\
\text { bo's robots and scenes are in 3D and it was held by } \\
t \text { the moment it is supported by OGRE [36,47,53]. }\end{array}$ \\
\hline & \multirow{6}{*}{ Features } & Robot Types & $\begin{array}{l}\text { Wheeled; Legged; Humanoids; Arms; Drones; } \\
\text { Others; }\end{array}$ \\
\hline & & $\begin{array}{l}\text { Sensors } \\
\text { and } \\
\text { Actuators }\end{array}$ & Several Sensors; Several Motors; \\
\hline & & Compatibility & Player; TCP/IP; ROS; Others; \\
\hline & & Engines & $\begin{array}{l}\text { ODE; Bullet; Simbody; DART; OpenGL; GLUT; } \\
\text { OGRE; }\end{array}$ \\
\hline & & $\begin{array}{l}\text { Programming } \\
\text { Languages }\end{array}$ & $\mathrm{XML} ; \mathrm{C}++;$ \\
\hline & & Other Features & $\begin{array}{l}\text { Users can add new robots models, sensors and } \\
\text { actuators; 3D Visualization; Open-Source; Sensors } \\
\text { and Noise; Plugins; Robot Models; Cloud Simulation; } \\
\text { Command Line Tools; Free to Use; }\end{array}$ \\
\hline Webots & Description & $\begin{array}{r}\text { Webots simulator is an open sour } \\
\text { It provides a complete dev } \\
\text { It has been designes } \\
\text { education and research. It was } \\
\text { The main features about We } \\
\text { the ODE fork physics engine and } \\
\text { C }++, \text { Python, Ja } \\
\text { of robots as wheeled, } \\
\text { flying drones, au }\end{array}$ & $\begin{array}{l}\text { form desktop application applied to simulate robots. } \\
\text { Iment to model, program and simulate robots. } \\
\text { l use, and it is widely used in industry, } \\
\text { gerbotics Ltd. in } 1998 \text { and currently it is free to use. } \\
\text { tation of a modern graphical user interface (Qt), } \\
\text { ering engine. The robot's programming may be in C, } \\
\text { ROS. It can simulate a wide variety } \\
\text { ipeds, multi-legs, modular, automobiles, } \\
\text { water, tracked and aerospace [46,82]. }\end{array}$ \\
\hline
\end{tabular}


Table 5. Cont.

\begin{tabular}{|c|c|c|c|}
\hline \multicolumn{4}{|c|}{ Simulators } \\
\hline & \multirow{6}{*}{ Features } & Robot Types & $\begin{array}{l}\text { Two-Wheeled; Arms; Bipeds; Multi-legs; Modular; } \\
\text { Automobiles; Drones; Autonomous Underwater; } \\
\text { Tracked; Aerospace }\end{array}$ \\
\hline & & Sensors and Actuators & Several Sensors; Several Motors; \\
\hline & & Compatibility & ROS; TCP/IP; MATLAB; Others; \\
\hline & & Engines & Qt; ODE; OpenGL \\
\hline & & $\begin{array}{l}\text { Programming } \\
\text { Languages }\end{array}$ & C/C++; Python; Java; MATLAB; ROS; \\
\hline & & Other Features & $\begin{array}{l}\text { Users can add new robot models, sensors and } \\
\text { actuators; 3D Visualization; Open-Source; Asset } \\
\text { Library of Robots, Sensors and Actuators, Objects } \\
\text { and Materials; Free and Paid Versions; }\end{array}$ \\
\hline \multirow{7}{*}{ SimTwo } & Description & $\begin{array}{l}\text { The SimTwo is a versatile ro } \\
\text { design of differential, omn } \\
\text { It also has a set of predefinec } \\
\text { models are inputted. R } \\
\text { Open Dynamics Engine, anc } \\
\text { XML format files. The visu } \\
\text { SimTwo is a frees }\end{array}$ & $\begin{array}{l}\text { environment that allows the rapid test and } \\
\text { dustrial, humanoid robot and other types. } \\
\text { such as sensors and motors, where specified } \\
\text { ody dynamics is possible thanks to the } \\
\text { he robots' look and behaviors are written in } \\
\text { 3D, and that is provided through GLScene. } \\
\text { currently open source }[38,41,48] \text {. }\end{array}$ \\
\hline & \multirow{6}{*}{ Features } & Robot Types & $\begin{array}{l}\text { Wheeled; Omnidirectional; Industrial; Humanoids; } \\
\text { Others; }\end{array}$ \\
\hline & & $\begin{array}{l}\text { Sensors } \\
\text { and } \\
\text { Actuators }\end{array}$ & Several Sensors; Several Motors; \\
\hline & & Compatibility & ROS; MATLAB; LabView; UDP Protocol; Others; \\
\hline & & Engines & ODE; Physics Abstraction Layer; GLScene; OpenGL; \\
\hline & & $\begin{array}{l}\text { Programming } \\
\text { Languages }\end{array}$ & XML; C/C++; MATLAB; Labview; \\
\hline & & Other Features & $\begin{array}{l}\text { Asset Library of Robots, Sensors and Actuators, } \\
\text { Objects and Materials; 3D Visualization; Free to Use; }\end{array}$ \\
\hline \multirow{7}{*}{ ARGoS } & Description & $\begin{array}{r}\text { Autonomous Robots Go S } \\
\text { designed to study tools an } \\
\text { It initially was released for } \mathrm{L} \\
\text { systems. The core of its arc } \\
\text { can be implemented in } \\
\text { components instead of the } \\
\text { already existing compon } \\
\text { components working without } \\
\text { types and can run in paralle } \\
\text { on the Open Dynamics Engin } \\
\text { physics engine library Ch } \\
\text { visualization has a g } \\
\text { ARGoS and th }\end{array}$ & $\begin{array}{l}\text { pen source multi-robot simulator that was } \\
\text { egies for heterogeneous swarms of robots. } \\
\text { OS X, and in } 2016 \text { was updated to Windows } \\
\text { simulated 3D space. Sensors and actuators } \\
\text { fficient way, taking into account specific } \\
\text { t. New robots can be inserted, reusing the } \\
\text { sensors/actuators, depending on those } \\
\text { ARGoS supports multiple engines of different } \\
\text { eeriment. The 3D dynamics engine is based } \\
\text { lynamics engine depends on the open-source } \\
\text { either a 3D or 2D custom engine. The 3D } \\
\text { nterface based on Qt4 and OpenGL. } \\
\text { ace are written in C++ }[30,83] \text {. }\end{array}$ \\
\hline & \multirow{6}{*}{ Features } & Robot Types & Swarm Robotics \\
\hline & & $\begin{array}{l}\text { Sensors } \\
\text { and } \\
\text { Actuators }\end{array}$ & Custom Sensors; Custom Motors; \\
\hline & & Compatibility & Not Applicable \\
\hline & & Engines & $\begin{array}{l}\text { ODE; Chipmunk; Custom 2D and 3D Engine; Qt: } \\
\text { OpenGL; }\end{array}$ \\
\hline & & $\begin{array}{l}\text { Programming } \\
\text { Languages }\end{array}$ & $\mathrm{C}++$ \\
\hline & & Other Features & $\begin{array}{l}\text { Users can add new robot models, sensors and } \\
\text { actuators; 3D Visualization; Open-Source; Free } \\
\text { to Use; }\end{array}$ \\
\hline Stage/Player & Description & $\begin{array}{l}\text { Stage is a robot simulator } \\
\text { and sensors in a two-dimen } \\
\text { for the robots to sense and } \mathrm{m} \\
\text { including sonar or infrarec } \\
\text { fiducial tracking, bumpers, } \\
\text { localization. The main usag } \\
\text { for swarm robotics and othe } \\
\text { of interest. Player is a netwo } \\
\text { provide a simple and clea }\end{array}$ & $\begin{array}{l}\text { virtual world populated by mobile robots } \\
\text { ed environment, along with various objects } \\
\text { rovides several sensor and actuator models, } \\
\text { ning laser rangefinder, color-blob tracking, } \\
\text { nobile robot bases with odometric or global } \\
\text { massively multi-robot experiments, suitable } \\
\text { re the behavior of large robot populations is } \\
\text { obot control. By running on the robot, it can } \\
\text { the robot's sensors and actuators over the } \\
38,39,57,60,84]\end{array}$ \\
\hline
\end{tabular}


Table 5. Cont.

\begin{tabular}{|c|c|c|c|}
\hline & & Simulators & \\
\hline & \multirow{6}{*}{ Features } & Robot Types & Swarm Robotics; Several Robot Models; \\
\hline & & $\begin{array}{l}\text { Sensors } \\
\text { and } \\
\text { Actuators }\end{array}$ & Several Sensors Models; Several Motors; \\
\hline & & Compatibility & Player; \\
\hline & & Engines & Custom Engine \\
\hline & & $\begin{array}{l}\text { Programming } \\
\text { Languages }\end{array}$ & C++; TCL; Java; Python; \\
\hline & & Other Features & $\begin{array}{c}\text { Users can add new robot models, sensors and } \\
\text { actuators; 2D Visualization; Open-Source; Free } \\
\text { to Use; }\end{array}$ \\
\hline \multirow{7}{*}{ MORSE } & Description & $\begin{array}{r}\text { MORSE is a gener } \\
\text { 3D simulation from } \\
\text { to tenths of auto } \\
\text { command-line. Sim } \\
\text { MORSE comes with } \\
\text { laser scanners, GPS, } \\
\text { joint controllers, and so f } \\
\text { vehicles, and new } \\
\text { Blender Game Engine for } \mathrm{r}\end{array}$ & $\begin{array}{l}\text { demic robotics. It focuses on realistic } \\
\text { ronments, indoor or outdoor, from one } \\
\text { can be entirely controlled from the } \\
\text { generated from simple Python scripts. } \\
\text { ensors and actuators such as cameras, } \\
\text { igh-level waypoints controllers, generic } \\
\text { otic bases as quadrotors, generic four wheel } \\
\text { added. This simulator is based on the } \\
\text { ullet engine for physics simulation [57,85-87]. }\end{array}$ \\
\hline & \multirow{6}{*}{ Features } & Robot Types & Wheeled; Quadrotors; Others; \\
\hline & & $\begin{array}{l}\text { Sensors } \\
\text { and } \\
\text { Actuators }\end{array}$ & Cameras; Laser Scanner; GPS; Speed Controllers; \\
\hline & & Compatibility & ROS; YARP; Pocolibs; MOOS; HLA; Mavlink; \\
\hline & & Engines & Blender Game Engine; Bullet \\
\hline & & $\begin{array}{l}\text { Programming } \\
\text { Languages }\end{array}$ & Python \\
\hline & & Other Features & $\begin{array}{c}\text { Users can add new robot models, sensors and } \\
\text { actuators; 3D Visualization; Open-Source; Free to } \\
\text { Use; Asset Library of Robots, Sensors and Actuators, } \\
\text { Objects and Materials; }\end{array}$ \\
\hline \multirow{7}{*}{ STDR } & Description & $\begin{array}{r}\text { Simple Two Dimensional } \mathrm{R} \\
\text { a single robot's or sh } \\
\text { it is not meant to be th } \\
\text { to perform a experiment } \\
\text { which allows for ex }\end{array}$ & $\begin{array}{l}\text { the title, the STDR simulator's goal is to make } \\
\text { as simple as possible; as a consequence, } \\
\text { ulator, by minimizing the needed actions } \\
\text { n with or without a graphical environment, } \\
\text { place even using ssh connections [57]. }\end{array}$ \\
\hline & \multirow{6}{*}{ Features } & Robot Types & Not Applicable \\
\hline & & $\begin{array}{l}\text { Sensors } \\
\text { and } \\
\text { Actuators }\end{array}$ & Not Applicable \\
\hline & & Compatibility & Not Applicable \\
\hline & & Engines & Not Applicable \\
\hline & & $\begin{array}{l}\text { Programming } \\
\text { Languages }\end{array}$ & Not Applicable \\
\hline & & Other Features & Not Applicable \\
\hline V-REP (CoppeliaSim) & Description & $\begin{array}{r}\text { The Virtual Rob } \\
\text { turning all requiren } \\
\text { According to its website } \\
\text { V-REP was disco } \\
\text { Robot Simulator an } \\
\text { on a distributed co } \\
\text { can be individu } \\
\text { BlueZero node, } \\
\text { is very versatile ar } \\
\text { written in C/C++ } \\
\text { for fast algorith } \\
\text { prototyping and ve } \\
\text { safety double-che }\end{array}$ & $\begin{array}{l}\text { Platform or V-REP is the result of } \\
\text { le and scalable simulation framework. } \\
\text { eliarobotics.com/, accessed on } 8 \text { June 2021, } \\
\text { ber } 262019 \text {, becoming CoppeliaSim } \\
\text { ated development environment based } \\
\text { which means that each object/model } \\
\text { an embedded script such as ROS, } \\
\text { or a custom solution. CoppeliaSim } \\
\text { obot applications. Controllers can be } \\
\text { Matlab or Octave. It can be applied } \\
\text { ctory automation simulations, fast } \\
\text { related education, remote monitoring, } \\
\text { win, and much more }[43,49,77,78,88] \text {. }\end{array}$ \\
\hline
\end{tabular}


Table 5. Cont.

\begin{tabular}{|c|c|c|c|}
\hline & & Simulators & \\
\hline & \multirow{6}{*}{ Features } & Robot Types & multi-robots \\
\hline & & $\begin{array}{l}\text { Sensors } \\
\text { and } \\
\text { Actuators }\end{array}$ & multi-sensors \\
\hline & & Compatibility & ROS; BlueZero; LabView; TCP/IP; \\
\hline & & Engines & Bullet; ODE; Vortex; Newton; \\
\hline & & $\begin{array}{l}\text { Programming } \\
\text { Languages }\end{array}$ & $\begin{array}{l}\text { C/C++; Lua; Java; Python; LabView; } \\
\text { MATLAB; Octave; }\end{array}$ \\
\hline & & Other Features & $\begin{array}{c}\text { Asset Library of Robots, Sensors and Actuators, } \\
\text { Objects and Materials; 3D Visualization; Free and } \\
\text { Paid Versions; }\end{array}$ \\
\hline \multirow{7}{*}{ RoSoS } & Description & $\begin{array}{l}\text { Robot Soccer } \\
\text { programmed usi } \\
\text { 1. the program for } \\
\text { robot; and } 2 \text {. use } \\
\text { operation, suc } \\
\text { their robots. It }\end{array}$ & $\begin{array}{l}\text { ator platform that was built and } \\
\text { age, and considers two guidelines: } \\
\text { ld be similar to the program of a real } \\
\text { ossibility to change the simulator } \\
\text { ne rules, and also to personalize } \\
\text { and runs on Windows, Mac OS } \\
\text { x [37]. }\end{array}$ \\
\hline & \multirow{6}{*}{ Features } & Robot Types & Soccer Robots \\
\hline & & $\begin{array}{l}\text { Sensors } \\
\text { and } \\
\text { Actuators }\end{array}$ & Ball Sensor; Compass Sensor; Ultrassonic Sensor; \\
\hline & & Compatibility & Not Applicable \\
\hline & & Engines & Custom Engine \\
\hline & & $\begin{array}{c}\text { Programming } \\
\text { Languages }\end{array}$ & C++; Java; \\
\hline & & Other Features & $\begin{array}{l}\text { Noise and Imprecisions; 2D Visualization; } \\
\text { Open-Source; Free to Use; }\end{array}$ \\
\hline \multirow{7}{*}{ UberSim } & Description & $\begin{array}{r}\text { A Multi-Robot } \\
\text { open-source sim } \\
\text { simulation eng } \\
\text { and extensible robc } \\
\text { A search was } \\
\text { ÜberSim simu } \\
\text { website wo }\end{array}$ & $\begin{array}{l}\text { Soccer was created as a free and } \\
\text { he objective of being a robot soccer } \\
\text { y dynamics and collision models } \\
\text { on the Open Dynamics Engine [76]. } \\
\text { ain more information about the } \\
\text { information was found, even its } \\
\text { as considered discontinued. }\end{array}$ \\
\hline & \multirow{6}{*}{ Features } & Robot Types & Multi-Agent Systems; Artifial Life; \\
\hline & & $\begin{array}{l}\text { Sensors } \\
\text { and } \\
\text { Actuators }\end{array}$ & Not Applicable \\
\hline & & Compatibility & Not Applicable \\
\hline & & Engines & OpenGL; \\
\hline & & $\begin{array}{l}\text { Programming } \\
\text { Languages }\end{array}$ & Python; Steve; \\
\hline & & Other Features & 3D Visualization; Free to Use; Open-Source; \\
\hline Breve & Description & $\begin{array}{r}\text { Breve is a free, op } \\
\text { 3D simulations of } \\
\text { using a simple scrip } \\
\text { agents in a 3D worl } \\
\text { simulation and coll } \\
\text { and to use an } \mathrm{O} \\
\text { However, according to its } \\
\text { the project has no } \\
\text { down }\end{array}$ & $\begin{array}{l}\text { package that makes it easy to build } \\
\text { and artificial life. Using Python, or } \\
\text { steve, you can define the behaviors of } \\
\text { hey interact. Breve includes physical } \\
\text { oossible to simulate realistic creatures } \\
\text { ne to visualize simulated worlds. } \\
\text { tspiderland.org/s/, accessed on } 8 \text { June 2021, } \\
\text { ince } 2009 \text {, but it is still available for } \\
\text { inux and Mac OS [40]. }\end{array}$ \\
\hline
\end{tabular}


Table 5. Cont.

\begin{tabular}{|c|c|c|c|}
\hline & & Simulators & \\
\hline & \multirow{6}{*}{ Features } & Robot Types & $\begin{array}{l}\text { Wheeled; Legged; Humanoids; Arms; } \\
\text { Drones; Others; }\end{array}$ \\
\hline & & $\begin{array}{l}\text { Sensors } \\
\text { and } \\
\text { Actuators }\end{array}$ & Several Sensors; Several Motors; \\
\hline & & Compatibility & Player; TCP/IP; ROS; Others; \\
\hline & & Engines & $\begin{array}{l}\text { ODE; Bullet; Simbody; DART; OpenGL; } \\
\text { GLUT; OGRE; }\end{array}$ \\
\hline & & $\begin{array}{l}\text { Programming } \\
\text { Languages }\end{array}$ & $\mathrm{XML} ; \mathrm{C}++;$ \\
\hline & & Other Features & $\begin{array}{c}\text { Users can add new robots models, sensors and } \\
\text { actuators; 3D Visualization; Open-Source; } \\
\text { Sensors and Noise; Plugins; Robot Models; } \\
\text { Cloud Simulation; Command Line Tools; } \\
\text { Free to Use; }\end{array}$ \\
\hline \multirow{7}{*}{ TeamBots } & Description & $\begin{array}{l}\text { TeamBots is a } 2 \mathrm{D} \text { Jav } \\
\text { The simulation enviro } \\
\text { multiple heterogeneo } \\
\text { Complex (or simple) ex } \\
\text { opponent robots and } \\
\text { simulation by editing } \\
\text { TeamBots runs unde } \\
\text { about this simulator wa } \\
\text { was updated i }\end{array}$ & $\begin{array}{l}\text { multi-agent mobile robotics research. } \\
\text { are written mostly in Java. It supports } \\
\text { inning heterogeneous control systems. } \\
\text { hents can be designed with walls, roads, } \\
\text { l of these objects may be included in a } \\
\text { dable human-readable description file. } \\
\text { d MacOS. The search for information } \\
\text { d since the latest version of this platform } \\
\text { e considered discontinued [60]. }\end{array}$ \\
\hline & \multirow{6}{*}{ Features } & Robot Types & Nomad 150; Cye Robot; \\
\hline & & $\begin{array}{l}\text { Sensors } \\
\text { and } \\
\text { Actuators }\end{array}$ & Not Applicable \\
\hline & & Compatibility & Not Applicable \\
\hline & & Engines & Not Applicable \\
\hline & & $\begin{array}{l}\text { Programming } \\
\text { Languages }\end{array}$ & Java \\
\hline & & Other Features & 2D Visualization; Free to Use; Open-Source; \\
\hline \multirow[t]{7}{*}{ MuRoSimF } & Description & $\begin{array}{r}\text { The Multi-Robot-Sim } \\
\text { generate interactive sin } \\
\text { biped and multi-legg } \\
\text { MuRoSimF is not limited to pred } \\
\text { Instead of this } \\
\text { simulation models of the rob } \\
\text { which are scalc } \\
\text { and computational } \\
\text { that are adequate } \\
\text { for mobile robots includi } \\
\text { MuRoSimF provides } \\
\text { (kinematic, sim } \\
\text { collision detection an } \\
\text { and inertial sensors). More } 1\end{array}$ & $\begin{array}{l}\text { (MuRoSimF) provides an easy way to } \\
\text { ion and sensing capabilities of wheeled, } \\
\text { st existing robot simulation packages, } \\
\text { orithms (e.g., for dynamics or sensor simulation). } \\
\text { and modular way to combine } \\
\text { By this, it is possible to generate simulations, } \\
\text { hysical accuracy, level of detail } \\
\text { bling the user to create simulations } \\
\text { g MuRoSimF, several simulations } \\
\text { id four-legged devices have been created. } \\
\text { able algorithms for motion simulation } \\
\text { l multi-body-system dynamics), } \\
\text { including cameras, laser range finders } \\
\text {, for detailed simulation of servo motors can } \\
\text { ework easily [89]. }\end{array}$ \\
\hline & \multirow{6}{*}{ Features } & Robot Types & Wheeled; Bipeds; Multi-Legged \\
\hline & & $\begin{array}{l}\text { Sensors } \\
\text { and } \\
\text { Actuators }\end{array}$ & Cameras; Laser Range Finders; Inertial Sensors; \\
\hline & & Compatibility & Not Applicable \\
\hline & & Engines & OpenGL; Custom Dynamics Engine; \\
\hline & & $\begin{array}{l}\text { Programming } \\
\text { Languages }\end{array}$ & $\mathrm{C}++$ \\
\hline & & Other Features & $\begin{array}{l}\text { 2D Visualization; 3D Visualization; } \\
\text { Free to Use; Open-Source; }\end{array}$ \\
\hline
\end{tabular}


Table 5. Cont.

\section{Simulators}

Microsoft Robotics Studio is an environment for robot control and simulation. It was designed for academic, hobbyist and commercial developers, and it also contains a wide variety of robot hardware. A point to note about this simulator is that it is only available on the Windows operational system. The main features include the Microsoft Visual Programming Language for creating and

Description

debugging robot applications and 3D simulation with access to the robot's sensors and actuators. Unfortunately, this simulator was discontinued in 2012 [90-92].

Microsoft

Robotics

Studio
Robot Types

Sensors

and Actuators

Features

\begin{tabular}{c} 
Compatibility \\
\hline Engines \\
\hline Programming
\end{tabular}

multi-robots

Several Sensors; Several Motors;

Other Features

D Visualization; Free and Paid Versions; Discontuated;

Open Architecture Human-centered Robotics Platform version 3 is a

platform for robot simulations and software developments, and it is

mainly applied for humanoid robot simulations. It allows users to check

Description

out a robot model and control program by dynamics simulation.

The simulator has a custom dynamics engine and graphical interface. The last version was released in $2012[93,94]$

Robot Types Humanoids

OpenHRP3

Sensors

and

Several Sensors; Several Motors;

Actuators

Features

Compatibility

Engines

Engine;

Programming

Languages

$\mathrm{C}++$

Other Features

3D Visualitation; Free to Use; Open-Source;

jmeSim is an open source, multi-robot platform; it provides high graphical and physical fidelity and also supports ROS integration. It was built on the jMonkey Engine3 game engine. The physics dynamics simulation

Description

is performed by jBullet, a Java port of the Bullet Physics Engine Library.

The jmeSim offers some environment and robot models, such as the wheeled rescue robot for example, and also provides an array of sensors [58].

Robot Types

multi-robots

jmeSim

Sensors

and

Actuators

Features

Compatibility

Engines

Programming

Languages

Other Features

Several Sensors; Several Motors;

Khepera Simulator is a freeware public domain software written by Oliver
Michel, and was designed to simulate the Khepera robot. This package allows the programmer to write control algorithms using $C / C++$ language.

Description

The simulator runs on Unix operational system and it has X11 as graphical interface.

This simulator features the ability to drive a real Khepera robot, then

the outcome of the simulation test can be easily transferred to a real

Khepera robot. No further information about this simulator was found and its website, presented in [95], is not available.

Khepera

\begin{tabular}{lc} 
Robot Types & Khepera Robots \\
$\begin{array}{c}\text { Sensors } \\
\text { and } \\
\text { Actuators }\end{array}$ & Not Applicable \\
Compatibility & Not Applicable \\
\hline Engines & $\mathrm{X} 11$ \\
\hline $\begin{array}{l}\text { Programming } \\
\text { Languages }\end{array}$ & $\mathrm{C} / \mathrm{C}++$ \\
\hline Other Features & 2D Visualization; Free to Use; Discontinuated; \\
\hline
\end{tabular}


Table 5. Cont.

\section{Simulators}

The simulator Delta3D is an open source game and simulation engine built for military training. Delta3d is a widely used, community-supported, open-source game and simulation engine. Delta3d is appropriate for a wide variety of uses including training, education, visualization and entertainment. Delta3d is unique because it offers features specifically suited to the Modeling, Simulation and

DoD communities, such as the High Level Architecture (HLA), After Action Review (AAR), large scale terrain support and SCORM Learning Management

System (LMS) integration. It has a modular design integrating other engines such as Open Scene Graph, Open Dynamics Engine, Character Animation Library and OpenAL. The renders engine uses the Open Graphics Library.

Delta3D

The last version released was on September 292014 and it is held on Github [96,97]

Features

\begin{tabular}{cl} 
Robot Types & Not Applicable \\
\hline $\begin{array}{c}\text { Sensors } \\
\text { and } \\
\text { Actuators }\end{array}$ & Not Applicable \\
\hline Compatibility & Not Applicable \\
\hline
\end{tabular}

Engines

Open Scene Graph; ODE;

Character Animation Library; OpenAL; Open Graphics Library;

Programming

Languages

$\mathrm{C}++$

Other Features

3D Visualization; Free to Use; Open-Source; Military Purpose,

MATLAB is a powerful general software that aids scientists, researchers and companies in several engineering/science areas, such as control systems, deep learning, image processing and computer vision, machine learning, predictive maintenance, robotics, signal processing, test and measurement of data and wireless communications. Simulink is a block diagram environment for multi domain simulation and Model-Based Design. It supports system-level design, simulation, automatic code generation and continuous testing and

verification of embedded systems. Simulink provides a graphical editor,

Description

customized block libraries, and solvers for modeling and simulating dynamic systems. It is integrated with MATLAB, enabling the incorporation of MATLAB algorithms into models and the export of simulation results to MATLAB for further analysis. In the robotics field, MATLAB with Simulink is one of the most used

platforms for the modeling and simulation of several systems. Many features

MATLAB/ Simulink can be added for the simulation, as well as the simulation of dynamics and graphical modelling, with the possibility of working in real time. To accomplish these features, it needs to be added that it is called "toolboxes" [1,98-101]

\begin{tabular}{|c|c|c|c|}
\hline & & & \\
\hline \multirow{13}{*}{ Swarmbot3D } & \multirow{6}{*}{ Features } & \multirow{2}{*}{$\begin{array}{c}\text { Robot Types } \\
\text { Sensors } \\
\text { and } \\
\text { Actuators }\end{array}$} & \multirow{2}{*}{$\begin{array}{c}\text { Any Robot Type } \\
\text { Any Type }\end{array}$} \\
\hline & & & \\
\hline & & Compatibility & Several Possibilities \\
\hline & & Engines & Custom Engine \\
\hline & & $\begin{array}{l}\text { Programming } \\
\text { Languages }\end{array}$ & Several Languages Supported \\
\hline & & Other Features & 2D and 3D Visualization; Paid; \\
\hline & Description & \multicolumn{2}{|c|}{$\begin{array}{l}\text { Swambot3d was designed for predicting the 3D kinematics and dynamics of } \\
\text { a single s-bot in a swarm-bot. The main characteristics of this simulation } \\
\text { environment are: 3D dynamics, compatibility with the s-bot's hardware } \\
\text { and software, interactive control, multi-level models and swarm handling, } \\
\text { and it was built using the Vortex physics engine. The simulation models } \\
\text { of the environment and robots are defined in an external test file written in } \\
\text { XML format. A search was evaluated to find this simulator on the } \\
\text { internet and no results were found [102-104]. }\end{array}$} \\
\hline & \multirow{6}{*}{ Features } & Robot Types & s-bot \\
\hline & & $\begin{array}{l}\text { Sensors } \\
\text { and } \\
\text { Actuators }\end{array}$ & Available under Modelling \\
\hline & & Compatibility & Not Applicable \\
\hline & & Engines & Vortex \\
\hline & & $\begin{array}{l}\text { Programming } \\
\text { Languages }\end{array}$ & XML \\
\hline & & Other Features & Not Applicable \\
\hline
\end{tabular}


Table 5. Cont.

\begin{tabular}{|c|c|c|c|}
\hline \multicolumn{4}{|c|}{ Simulators } \\
\hline \multirow{7}{*}{ Creo } & Description & $\begin{array}{r}\text { In [70] the authors } u \\
\text { robot using its virtual t } \\
\text { software from PTC Inc } \\
\text { approach is an interest } \\
\text { from the previously sho } \\
\text { software for produ } \\
\text { breakthrough innovations } \\
\text { multi-body desigr }\end{array}$ & $\begin{array}{l}\text { ate a humanoid } \\
\text { lade using the Creo } \\
\text {, but the presented } \\
\text { e a robot, differing } \\
\text { iputer-aided design } \\
\text { inge. Creo has } \\
\text {, real-time simulation, } \\
\text { ther features. }\end{array}$ \\
\hline & \multirow{6}{*}{ Features } & Robot Types & Not Applicable \\
\hline & & Sensors and Actuators & Not Applicable \\
\hline & & Compatibility & Not Applicable \\
\hline & & Engines & Not Applicable \\
\hline & & Programming Languages & Not Applicable \\
\hline & & Other Features & Not Applicable \\
\hline
\end{tabular}

\subsection{Exception Points}

This subsection describes some simulators and papers that were considered exceptions, found during the research of this SLR. Although they do not completely fulfill the previously defined requisites, they represent relevant work that it is worth to mention.

1. The first exception point to be discussed in the Table 3 is the Exception $\mathbf{1}$ found in the paper [61]. This paper has as its title: "Mathematical modelling, simulation and experimental verification of a Scara robot", from Das, M. T., \& Dülger, L. C. The authors developed a complete mathematical model of the Scara robot (Serpent 1 type robot), but the simulations carried out during the study were made using a numerical simulator such as MATLAB, and also they do not show how or which simulations were conducted. However, this paper could be replicated in another simulator such as the V-REP or Sim-Two, for example.

2. The next point that stands out as an exception (marked as Exception 2 in Table 3), is the paper [75], Cervera, Enric, et al., "The robot programming network". The authors present a system that allows the users to learn robotics topics in a virtual environment using a web-based laboratory with real robots or 2D/3D simulators. In this case, the system gathers tools that are fundamental for robotics learning such as learning the Robot Operating System use, including the possibility to try out in realistic and non-realistic simulators that are embedded into this web-based system.

3. Another reference that is an exception is [105], where the authors design a simulator with a realistic visualization of the head of IRYS robot. Although the simulator, made using the Unreal Engine, is realistic enough in what concern the robot motion and appearance, it is just to simulate this robot. For that reason it was categorized as an exception.

4. The last exception is the paper [106], in which the authors present an architecture for the management of a fleet of cleaning robots and, for this purpose, they design a simulator to evaluate its framework. The simulator has is called CleanSim and simulates map dirtiness; in this way, the authors can test their algorithm to improve the efficiency of the cleaning method. However, this is an exception for not being a realistic simulator based on a physics engine.

Future work could include the simulation shown in item 1 of this subsection, where the authors could replicate the modeling made in [61] with a realistic simulator. Another point to note is that, during the complete reading of the articles, some non-realistic simulators were found. However, they were discarded although they were used in educational contexts, as in the case of $[105,106]$; the main reason is because they were not based on a physics engine. 


\subsection{Physics Engines}

Throughout the search, reading and analyzing each paper and simulator, one common point stands out, that they are built with physics engines. Table 6 shows the physics engines found and a classification in different columns depending on if they are a free or a propietary solution.

Table 6. Physics Engines.

\begin{tabular}{cc}
\hline Free/Open-Source & Proprietary \\
\hline Box2D & AGX Multiphysics \\
Bullet & Algodoo \\
Cannon.js & Digital Molecular Matter \\
Chipmunk & Chipmunk \\
Newton Game Dynamics & Euphoria \\
Open Dynamics Engine & Havok \\
OPAL & Reactor \\
Physics Abstraction Layer & Vortex \\
PhysX & \\
PhyZ & \\
Project Chrono & \\
Siconos & \\
Simulation Open Framework Architecture & \\
\hline
\end{tabular}

As noted in Table 6, there are many available physics engines softwares; some are paid software and others free. In [7], an evaluation among five free physics engines is presented, and the author concludes that there is no general physics engine that performs best for any given task; each has its strengths and weaknesses. Taking this previous consideration into this work, simulators based on one or more physics engines will overlap the performance of those built with only one, and that is updated repeatedly.

\subsection{Robot Operating System-ROS}

Another common feature of the simulators found during the research was the Robot Operating System (ROS). ROS is a framework for writing robot software. It has several tools, libraries and conventions that aim to simplify the task of creating complex and robust robot behavior across a wide variety of robotics platforms. This framework emerged as an alternative way to create general-purpose robot software. ROS provides standard operating system services, such as hardware abstraction and low-level device control, the implementation of commonly used features, message-passing between processes, and package management. Sets of ROS processes in execution are represented in a graph architecture where processing occurs at nodes that can receive and send messages such as multiplex sensors, control, status, planning, actuator and others. Despite the importance of reactivity and low latency in robot control, ROS itself is not a real-time operating system. For this instance, ROS is an important, free and open-source tool in the robotics field, being widely used for makers, researchers and in the industry, and it is integrated into sundry simulators such as, Gazebo, Webots, MORSE, V-REP and others (https: / www.ros.org/, accessed on 8 June 2021) $[35,36,43,44,49,50,52,53,75,77,87,107-112]$.

\section{Conclusions and Future Work}

In this paper, a systematic literature review of realistic simulators applied in an educational context was conducted in order to evaluate whether there is any simulator capable of simulating a robot prototype using realistic world physics.

By performing this systematic review, questions were answered about the found papers, providing a current state-of-the-art and a view of this research field. During the review process, 559 papers were retrieved from six different electronic databases, from which 50 relevant papers were selected and included in this review, after applying the 
inclusion and exclusion criteria and the quality assessment. Table 7 shows how the selected papers address the research questions asked in Section 2.1.

Table 7. Selected papers that address the Research Questions.

\begin{tabular}{cc}
\hline Research Questions & Selected Papers \\
\hline & {$[30,32,33,36-38]$} \\
1: In the context of educational robotics, are there any realistic & {$[41-43,45,49,50]$} \\
simulators capable of simulating any robot prototype? & {$[51,54-57,59]$} \\
& {$[60,62-64,66,67]$} \\
& {$[69,71,73-76,78]$} \\
\hline & {$[30-35]$} \\
2: Are these simulators capable of simulating & {$[36,38,39,41-43]$} \\
the robot's sensores and/or actuators? & {$[44-49]$} \\
& {$[50-55]$} \\
& {$[56-61]$} \\
& {$[62-67]$} \\
& {$[68-73]$} \\
3: Is such simulation based on physical motors? & {$[3,74-78]$} \\
\hline & {$[37,38,40-46]$} \\
& {$[46-51]$} \\
\end{tabular}

Therefore, by reading, analyzing and gathering data from each relevant paper and simulator, some simulators have been shown to be promising tools to be used in the educational context for some reasons that we observed.

But first, coming back to answer the research questions (RQ1, RQ2 and RQ3): considering all the simulators presented in Table 3, the frequency that was cited in the papers by the different authors, as shown in Table 4, the simulators' features studied in Section 4.1 and Table 5, and finally, from the considerations made at the end of the previous paragraph and sections, it is possible to conclude that the simulators that can be easily applied in the educational context, are: Gazebo, Webots, SimTwo and V-REP.

The reasons for this are: firstly, the long time they have been available for use, that is, since their launch they continue to receive updates to keep up to date with the technology; The second characteristic observed was the number of platform and robots prototype variations (wheeled, legged, humanoids, drones and others) available to be used, or the possibility to add, configure and use a robot of your own in these simulators; in this way, allowing simulation in different environments, allowing a high level of abstraction with high fidelity in the simulation due to the use of physics engines. The third was the simulator's ability to execute the simulations under one or more physics engines; this is an indicator of how realistic the simulation is. Another important feature of these simulators is that all of them have 3D vision of the robot and the environment, giving us the feeling of working with the real robot, without having it; Finally, is the capability of integrating with third party systems or protocols, for example, the integration of Robot Operating System (ROS), TCP/IP, MATLAB, LabView and others.

As future work, it could be interesting to produce a framework that provides a guideline for modelling an actuator, sensor or the entire robot in order to upload it into one of these simulators to test our own robots with different actuators or sensors, and to test them in different environments, such as a maze arena and line-following circuits.

Author Contributions: All the authors have collaborate in the same way. All authors have read and agreed to the published version of the manuscript. 
Funding: This research received no external funding.

Conflicts of Interest: The authors declare no conflict of interest.

\begin{tabular}{|c|c|}
\hline \multicolumn{2}{|c|}{ Abbreviations } \\
\hline \multicolumn{2}{|c|}{ The following abbreviations are used in this manuscript: } \\
\hline SLR & Systematic Literature Review \\
\hline PICOC & Population, Intervention, Comparison, Outcomes, Context \\
\hline PRISMA & Preferred Reporting Items for Systematic Reviews and Meta-Analyses \\
\hline RQ & Research Question \\
\hline IC & Inclusion Criteria \\
\hline $\mathrm{EC}$ & Exclusion Criteria \\
\hline QQ & Quality Question \\
\hline DQ & Data Question \\
\hline ROS & Robot Operating System \\
\hline
\end{tabular}

\section{Appendix A. Data Repository}

https:/ / github.com/caioorafael/Systematic-Literature-Review-of-Realistic-Simulatorsto-be-applied-in-Educational-Context.git, accessed on 8 June 2021.

\section{References}

1. Žlajpah, L. Simulation in robotics. Math. Comput. Simul. 2008, 79, 879-897. [CrossRef]

2. Reckhaus, M.; Hochgeschwender, N.; Paulus, J.; Shakhimardanov, A.; Kraetzschmar, G.K. An overview about simulation and emulation in robotics. Proc. Simpar 2010, 365-374.

3. Williams, E.J.; Ülgen, O.M. Simulation Applications in the Automotive Industry. In Use Cases of Discrete Event Simulation; Bangsow S., Ed.; Springer: Berlin/Heidelberg, Germany, 2012.

4. Xu, J.; Huang, E.; Hsieh, L.; Lee, L.H.; Jia, Q.-S.; Chen, C.-H. Simulation optimization in the era of Industrial 4.0 and the Industrial Internet. J. Simul. 2016, 10, 310-320. [CrossRef]

5. Currie, C.S.; Fowler, J.W.; Kotiadis, K.; Monks, T.; Onggo, B.S.; Robertson, D.A.; Tako, A.A. How simulation modelling can help reduce the impact of COVID-19. J. Simul. 2020, 14, 83-97. [CrossRef]

6. Boeing, A.; Bräunl, T. Evaluation of real-time physics simulation systems. In Proceedings of the 5th International Conference on Computer Graphics and Interactive Techniques in Australia and Southeast Asia, Perth, Australia, 1-4 December 2007; pp. 281-288.

7. Hummel, J.; Wolff, R.; Stein, T.; Gerndt, A.; Kuhlen, T. An evaluation of open source physics engines for use in virtual reality assembly simulations. In International Symposium on Visual Computing; Springer: Berlin/Heidelberg, Germany, $2012 ;$ pp. 346-357.

8. Bourg, D.M.; Bywalec, B. Physics for Game Developers: Science, Math, and Code for Realistic Effects; O'Reilly Media, Inc.: Newton, MA, USA, 2013.

9. Millington, I. Game Physics Engine Development; CRC Press: Boca Raton, FL, USA, 2007.

10. Ferrada-Ferrada, C.; Carrillo-Rosúa, J.; Díaz-Levicoy, D.; Silva-Díaz, F. Robotics from STEM areas in Primary School: A Systematic Review. Educ. Knowl. Soc. 2020. [CrossRef]

11. Conde, M.Á.; Rodríguez-Sedano, F.J.; Fernández-Llamas, C.; Gonçalves, J.; Lima, J.; García-Peñalvo, F.J. Fostering STEAM through Challenge Based Learning, Robotics and Physical Devices: A systematic mapping literature review. Comput. Appl. Eng. Educ. 2021, 29, 46-65. [CrossRef]

12. García-Holgado, A.; Marcos-Pablos, S.; García-Peñalvo, F.J. Guidelines for performing Systematic Research Projects Reviews. Int. J. Interact. Multimed. Artif. Intell. 2020, 6, 136-144. [CrossRef]

13. Kitchenham, B. Procedures for Performing Systematic Reviews; Keele University: Keele, UK, 2004; Volume 33, pp. 1-26.

14. Kitchenham, B.; Charters, S. Guidelines for Performing Systematic Literature Reviews in Software Engineering; EBSE: Menen, Belgium, 2007.

15. Kitchenham, B.A.; Budgen, D.; Brereton, P. Evidence-Based Software Engineering and Systematic Reviews; CRC Press: Boca Raton, FL, USA, 2015; Volume 4.

16. Dyba, T.; Dingsoyr, T.; Hanssen, G.K. Applying systematic reviews to diverse study types: An experience report. In Proceedings of the First International Symposium on Empirical Software Engineering and Measurement (ESEM 2007), Madrid, Spain, 20-21 September 2007; pp. 225-234.

17. Cooper, H.M. Synthesizing Research: A Guide for Literature Reviews; Sage: Beijing, China, 1998; Volume 2.

18. Orwin, R.G.; Cooper, I.H.; Hedges, L.V. The Handbook of Research Synthesis; Russell Sage Foundation: New York, NY, USA, 1994; pp. 139-162.

19. Dybå, T.; Kampenes, V.B.; Sjøberg, D.I.K. A Systematic Review of Statistical Power in Software Engineering Experiments. Inf. Softw. Technol. 2006, 48, 745-755. [CrossRef] 
20. Higgins, J.P.T.; Green, S. (Eds.) Cochrane Handbook for Systematic Reviews of Interventions 4.2.5 [updated May 2005]. In The Cochrane Library; Issue 3; John Wiley \& Sons, Ltd.: Chichester, UK, 2005.

21. Mulrow, C.; Cook, D. (Eds.) Systematic Reviews: Synthesis of Best Evidence for Health Care Decisions; Am. College of Physicians: Philadelphia, PA, USA, 1998.

22. Petticrew, M.; Roberts, H. Systematic Reviews in the Social Sciences: A Practical Guide; Blackwell: Oxford, UK, 2006.

23. Popay, J.; Roberts, H.; Sowden, A.; Petticrew, M.; Britten, N.; Arai, L.; Roen, K.; Rodgers, M. Developing guidance on the conduct of narrative synthesis in systematic reviews. J. Epidemiol. Community Health 2005, 59 (Suppl. 1), A7.

24. Jpt Chh, G.S. Cochrane Handbook for Systematic Reviews of Interventions Version 5.1. 0; [Updated March 2011]; The Cochrane Collaboration: London, UK, 2011.

25. La, A.H.; Szabo, I.; Le Brun, L.; Owen, I.; Fletcher, G.; Hill, M. An evidence-based approach to scoping reviews. Electron. J. Inf. Syst. Eval. 2011, 14, 46.

26. Ferreras-Fernández, T.; Martín-Rodero, H.; García-Peñalvo, F.J.; Merlo-Vega, J.A. The systematic review of literature in LIS: An approach. In Proceedings of the Fourth International Conference on Technological Ecosystems for Enhancing Multiculturality, Salamanca, Spain, 2-4 November 2016; pp. 291-296.

27. Rodero, H.M. La búSqueda Bibliográfica, Pilar Fundamental de la Medicina Basada en la Evidencia: Evaluación Multivariante en las Enfermedades Nutricionales y Metabólicas. Ph.D. Thesis, Universidad Miguel Hernández, Elche, Spain, 2014.

28. Moher, D.; Altman, D.G.; Liberati, A.; Tetzlaff, J. PRISMA statement. Epidemiology 2011, 22, 128. [CrossRef]

29. Moher, D.; Liberati, A.; Tetzlaff, J.; Altman, D.G.; Prisma Group. Preferred reporting items for systematic reviews and metaanalyses: The PRISMA statement. PLoS Med. 2009, 6, e1000097. [CrossRef] [PubMed]

30. Pinciroli, C.; Trianni, V.; O’Grady, R.; Pini, G.; Brutschy, A.; Brambilla, M.; Mathews, N.; Ferrante, E.; Di Caro, G.; Ducatelle, F.; et al. ARGoS: A modular, multi-engine simulator for heterogeneous swarm robotics. In Proceedings of the 2011 IEEE/RSJ International Conference on Intelligent Robots and Systems, San Francisco, CA, USA, 25-30 September 2011; pp. 5027-5034.

31. Gonçalves, J.; Lima, J.; Costa, P.G. DC motors modeling resorting to a simple setup and estimation procedure. In CONTROLO'2014-Proceedings of the 11th Portuguese Conference on Automatic Control; Springer: Cham, Switzerland, 2015 ; pp. $441-447$.

32. Lima, J.L.; Goncalves, J.C.; Costa, P.G.; Moreira, A.P. Humanoid low-level controller development based on a realistic simulation. Int. J. Humanoid Robot. 2010, 7, 587-607. [CrossRef]

33. Lima, J.; Gonçalves, J.; Costa, P.; Moreira, A. Humanoid realistic simulator: The servomotor joint modeling. In Proceedings of the 6th International Conference on Informatics in Control, Automation and Robotics, Milan, Italy, 2-5 July 2009.

34. Lima, J.; Gonçalves, J.; Costa, P.; Moreira, A. Humanoid robot simulator: A realistic dynamics approach. In CONTROLO 2008-The 8th Portuguese Conference on Automatic Control; Springer: Cham, Switzerland, 2008.

35. Quigley, M.; Conley, K.; Gerkey, B.; Faust, J.; Foote, T.; Leibs, J.; Wheeler, R.; Ng, A.Y. ROS: An open-source Robot Operating System. ICRA Workshop Open Source Softw. 2009, 3, 5.

36. Afanasyev, I.; Sagitov, A.; Magid, E. ROS-based SLAM for a Gazebo-simulated mobile robot in image-based 3D model of indoor environment. In Proceedings of the International Conference on Advanced Concepts for Intelligent Vision Systems, Catania, Italy, 26-29 October 2015; pp. 273-283.

37. Martins, F.N.; Gomes, I.S.; Santos, C.R. RoSoS-A free and open-source robot soccer simulator for educational robotics. In Robotics; Springer: Cham, Switzerland, 2016; pp. 87-102.

38. Paulo, C.; José, G.; José, L.; Paulo, M. Simtwo realistic simulator: A tool for the development and validation of robot software. Theory Appl. Math. Comput. Sci. 2011, 1, 17-33.

39. Carpin, S.; Lewis, M.; Wang, J.; Balakirsky, S.; Scrapper, C. USARSim: A robot simulator for research and education. In Proceedings of the 2007 IEEE International Conference on Robotics and Automation, Roma, Italy, 10-14 April 2007; pp. $1400-1405$.

40. Klein, J.; Spector, L. 3d multi-agent simulations in the breve simulation environment. In Artificial Life Models in Software; Springer: London, UK, 2009; pp. 79-106.

41. Eckert, L.; Piardi, L.; Lima, J.; Costa, P.; Valente, A.; Nakano, A. 3D Simulator Based on SimTwo to Evaluate Algorithms in Micromouse Competition. In World Conference on Information Systems and Technologies; Springer: Cham, Swizterland, 2019; pp. 896-903.

42. Piardi, L.; Eckert, L.; Lima, J.; Costat, P.; Valente, A.; Nakano, A. 3D simulator with hardware-in-the-loop capability for the micromouse competition. In Proceedings of the 2019 IEEE International Conference on Autonomous Robot Systems and Competitions (ICARSC), Porto, Portugal, 24-26 April 2019; pp. 1-6.

43. Farias, G.; Fabregas, E.; Peralta, E.; Torres, E.; Dormido, S. A Khepera IV library for robotic control education using V-REP. IFAC-PapersOnLine 2017, 50, 9150-9155. [CrossRef]

44. Cervera, E.; Casañ, G.; Tellez, R. Cloud Simulations for RoboCup. In Robot World Cup; Springer: Cham, Swizterland, 2017; pp. $180-189$.

45. Ferrein, A.; Maier, C.; Mühlbacher, C.; Niemueller, T.; Steinbauer, G.; Vassos, S. Controlling logistics robots with the action-based language YAGI. In Proceedings of the International Conference on Intelligent Robotics and Applications, Tokyo, Japan, 22-24 August 2016; pp. 525-537.

46. Michel, O. Cyberbotics Ltd. Webots ${ }^{\mathrm{TM}}$ : Professional mobile robot simulation. Int. J. Adv. Robot. Syst. 2004, 1, 5. [CrossRef] 
47. Koenig, N.; Howard, A. Design and use paradigms for gazebo, an open-source multi-robot simulator. In Proceedings of the 2004 IEEE/RSJ International Conference on Intelligent Robots and Systems (IROS) (IEEE Cat. No. 04CH37566), Sendai, Japan, 28 September-2 October 2004; Volume 3, pp. 2149-2154.

48. Denisov, A.; Budkov, V.; Mikhalchenko, D. Designing simulation model of humanoid robot to study servo control system. In Proceedings of the International Conference on Interactive Collaborative Robotics, ICR 2016, Budapest, Hungary, 24-26 August 2016; pp. 69-78.

49. Peralta, E.; Fabregas, E.; Farias, G.; Vargas, H.; Dormido, S. Development of a Khepera IV Library for the V-REP Simulator. IFAC-PapersOnLine 2016, 49, 81-86. [CrossRef]

50. Chebotareva, E.; Gavrilova, L. Educational Mobile Robotics Project "ROS-Controlled Balancing Robot" Based on Arduino and Raspberry Pi. In Proceedings of the 2019 12th International Conference on Developments in eSystems Engineering (DeSE), Kazan, Russia, 7-10 October 2019; pp. 209-214.

51. Gonçalves, J.; Lima, J.; Malheiros, P.; Costa, P. Fostering advances in mechatronics and robotics resorting to simulation. IFAC Proc. Vol. 2010, 43, 326-331. [CrossRef]

52. Pinho, T.; Moreira, A.P.; Boaventura-Cunha, J. Framework using ROS and SimTwo simulator for realistic test of mobile robot controllers. In CONTROLO'2014-Proceedings of the 11th Portuguese Conference on Automatic Control; Springer: Cham, Swizterland, 2015; pp. 751-759.

53. Shimchik, I.; Sagitov, A.; Afanasyev, I.; Matsuno, F.; Magid, E. Golf cart prototype development and navigation simulation using ROS and Gazebo. In MATEC Web of Conferences; EDP Sciences: Les Ulis, France, 2016; Volume 75, p. 09005.

54. Lima, J.; Costa, P.; Brito, T.; Piardi, L. Hardware-in-the-loop simulation approach for the Robot at Factory Lite competition proposal. In Proceedings of the 2019 IEEE International Conference on Autonomous Robot Systems and Competitions (ICARSC), Porto, Portugal, 24-26 April 2019; pp. 1-6.

55. Lima, J.; Gonçalves, J.; Costa, P.; Moreira, A. Humanoid robot gait planning resorting to an adaptive simulated annealing algorithm. In Proceedings of the 10th Conference on Autonomous Robot Systems and Competitions, Leiria, Portugal, 24 March 2010.

56. Lima, J.L.; Gonçalves, J.C.; Costa, P.G.; Moreira, A.P. Humanoid robot simulation with a joint trajectory optimized controller. In Proceedings of the 2008 IEEE International Conference on Emerging Technologies and Factory Automation, Hamburg, Germany, 15-18 September 2008; pp. 986-993.

57. Ferreira, N.F.; Araujo, A.; Couceiro, M.S.; Portugal, D. Intensive summer course in robotics-Robotcraft. Appl. Comput. Inform. 2020. [CrossRef]

58. Haber, A.; McGill, M.; Sammut, C. Jmesim: An open source, multi platform robotics simulator. In Proceedings of the Australasian Conference on Robotics and Automation, Wellington, New Zealand, 3-5 December 2012.

59. Costa, P.J.; Moreira, N.; Campos, D.; Gonçalves, J.; Lima, J.; Costa, P.L. Localization and navigation of an omnidirectional mobile robot: the robot@ factory case study. IEEE Rev. Iberoam. Tecnol. Del Aprendiz. 2016, 11, 1-9. [CrossRef]

60. Vaughan, R. Massively multi-robot simulation in stage. Swarm Intell. 2008, 2, 189-208. [CrossRef]

61. Das, M.T.; Dülger, L.C. Mathematical modelling, simulation and experimental verification of a scara robot. Simul. Model. Pract. Theory 2005, 13, 257-271. [CrossRef]

62. Campos, D.; Santos, J.; Gonçalves, J.; Costa, P. Modeling and simulation of a hacked neato xv-11 laser scanner. In Robot 2015: Second Iberian Robotics Conference; Springer: Cham, Swizterland, 2016; pp. 425-436.

63. Lima, J.; Gonçalves, J.; Costa, P.J.; Moreira, A.P. Modeling and simulation of a laser scanner sensor: An industrial application case study. In Advances in Sustainable and Competitive Manufacturing Systems; Springer: Berlin/Heidelberg, Germany, 2013 ; pp. 245-258.

64. Gonçalves, J.; Lima, J.; Costa, P.J.; Moreira, A.P. Modeling and simulation of the emg30 geared motor with encoder resorting to simtwo: The official robot@ factory simulator. In Advances in Sustainable and Competitive Manufacturing Systems; Springer: Berlin/Heidelberg, Germany, 2013; pp. 307-314.

65. Lima, J.; Gonçalves, J.; Costa, P.J. Modeling of a low cost laser scanner sensor. In CONTROLO'2014-Proceedings of the 11th Portuguese Conference on Automatic Control; Springer: Berlin/Heidelberg, Germany, 2015; pp. 697-705.

66. Vega, J.; Cañas, J.M. PiBot: An open low-cost robotic platform with camera for STEM education. Electronics 2018, 7, 430. [CrossRef]

67. Gonçalves, J.; Silva, M.; Costa, P.; Sousa, A. Proposal of a low cost educational mobile robot experiment: An approach based on hardware and simulation. In Proceedings of the 6th Internation Conference on Robotics on Education, Yverdon-les-Bains, Switzerland, 21 May 2015.

68. Lima, J.; Gonçalves, J.; Costa, P.; Moreira, A. Realistic behaviour simulation of a humanoid robot. In Proceedings of the 8th Conference on Autonomous Robot Systems and Competitions, Aveiro, Portugal, 2-6 April 2008.

69. Gonçalves, J.; Lima, J.; Malheiros, P.; Costa, P. Realistic simulation of a lego mindstorms nxt based robot. In Proceedings of the 2009 IEEE Control Applications, (CCA) \& Intelligent Control, St. Petersburg, Russia, 8-10 July 2009; pp. $1242-1247$.

70. Verner, I.; Cuperman, D.; Fang, A.; Reitman, M.; Romm, T.; Balikin, G. Robot online learning through digital twin experiments: A weightlifting project. In Online Engineering E Internet of Things; Springer: Berlin/Heidelberg, Germany, 2018 ; pp. 307-314.

71. Braun, J.; Fernes, L.A.; Moya, T.; Oliveira, V.; Brito, T.; Lima, J.; Costa, P. Robot@ factory lite: An educational approach for the competition with simulated and real environment. In Proceedings of the Iberian Robotics Conference, Porto, Portugal, 20-22 November 2019; pp. 478-489. 
72. Gonçalves, J.; Lima, J.; Oliveira, H.; Costa, P. Sensor and actuator modeling of a realistic wheeled mobile robot simulator. In Proceedings of the 2008 IEEE International Conference on Emerging Technologies and Factory Automation, Hamburg, Germany, 15-18 September 2008; pp. 980-985.

73. Gonçalves, J.; Lima, J.; Malheiros, P.; Costa, P. Sensor and actuator stochastic modeling of the Lego Mindstorms NXT educational Kit. In Proceedings of the 10th Conference on Mobile Robots and Competitions, Leiria, Portugal, 24 March 2010; pp. 11-16.

74. Zwilling, F.; Niemueller, T.; Lakemeyer, G. Simulation for the RoboCup logistics league with real-world environment agency and multi-level abstraction. In Robot Soccer World Cup; Springer: Cham, Switzerland, 2014; pp. 220-232.

75. Cervera, E.; Martinet, P.; Marin, R.; Moughlbay, A.A.; Del Pobil, A.P.; Alemany, J.; Esteller, R.; Casañ, G. The robot programming network. J. Intell. Robot. Syst. 2016, 81, 77-95. [CrossRef]

76. Browning, B.; Tryzelaar, E. Übersim: a multi-robot simulator for robot soccer. In Proceedings of the Second International Joint Conference on Autonomous Agents and Multiagent Systems, Melbourne Australia, 14-18 July 2003; pp. 948-949.

77. Rohmer, E.; Singh, S.P.; Freese, M. V-REP: A versatile and scalable robot simulation framework. In Proceedings of the 2013 IEEE/RSJ International Conference on Intelligent Robots and Systems, Tokyo, Japan, 3-7 November 2013; pp. 1321-1326.

78. Gawryszewski, M.; Kmiecik, P.; Granosik, G. V-REP and LabVIEW in the Service of Education. In Robotics in Education; Springer: Berlin/Heidelberg, Germany, 2017; pp. 15-27.

79. Petry, M.; Moreira, A.P.; Reis, L.P.; Rossetti, R. Intelligent wheelchair simulation: Requirements and architectural issues. In Proceedings of the 11th International Conference on Mobile Robotics and Competitions, Lisbon, Portugal, 6 April 2011; pp. 102-107.

80. Boedecker, J.; Asada, M. Simspark-concepts and application in the robocup 3d soccer simulation league. Auton. Robot. 2008, $174,181$.

81. Xu, Y.; Vatankhah, H. Simspark: An open source robot simulator developed by the robocup community. In Robot Soccer World Cup; Springer: Berlin/Heidelberg, Germany, 2013; pp. 632-639.

82. Michel, O. Webots: Symbiosis between virtual and real mobile robots. In International Conference on Virtual Worlds; Springer: Berlin/Heidelberg, Germany, 1998; pp. 254-263.

83. Pinciroli, C.; Trianni, V.; O’Grady, R.; Pini, G.; Brutschy, A.; Brambilla, M.; Mathews, N.; Ferrante, E.; Di Caro, G.; Ducatelle, F. ARGoS: A modular, parallel, multi-engine simulator for multi-robot systems. Swarm Intell. 2012, 6, 271-295. [CrossRef]

84. Gerkey, B.; Vaughan, R.T.; Howard, A. The player/stage project: Tools for multi-robot and distributed sensor systems. In Proceedings of the 11th International Conference on Advanced Robotics, Coimbra, Portugal, 30 June-3 July 2003; Volume 1, pp. 317-323.

85. Lemaignan, S.; Echeverria, G.; Karg, M.; Mainprice, J.; Kirsch, A.; Alami, R. Human-robot interaction in the MORSE simulator. In Proceedings of the Seventh Annual ACM/IEEE International Conference on Human-Robot Interaction, Boston, MA, USA, 5-8 March 2012; pp. 181-182.

86. Echeverria, G.; Lassabe, N.; Degroote, A.; Lemaignan, S. Modular open robots simulation engine: Morse. In Proceedings of the 2011 IEEE International Conference on Robotics and Automation, Shanghai, China, 9-13 May 2011; pp. 46-51.

87. Noori, F.M.; Portugal, D.; Rocha, R.P.; Couceiro, M.S. On 3D simulators for multi-robot systems in ROS: MORSE or Gazebo? In Proceedings of the 2017 IEEE International Symposium on Safety, Security and Rescue Robotics (SSRR), Shanghai, China, 11-13 October 2017; pp. 19-24.

88. Freese, M.; Singh, S.; Ozaki, F.; Matsuhira, N. Virtual robot experimentation platform v-rep: A versatile 3d robot simulator. In Proceedings of the International Conference on Simulation, Modeling, and Programming for Autonomous Robots, Darmstadt, Germany, 15-18 November 2010; pp. 51-62.

89. Friedmann, M. Simulation of Autonomous Robot Teams with Adaptable Levels of Abstraction. Ph.D. Thesis, Technische Universität, Berlin, Germany, 2010.

90. Jackson, J. Microsoft robotics studio: A technical introduction. IEEE Robot. Autom. Mag. 2007, 14, 82-87. [CrossRef]

91. Cepeda, J.S.; Chaimowicz, L.; Soto, R. Exploring Microsoft Robotics Studio as a mechanism for service-oriented robotics. In Proceedings of the 2010 Latin American Robotics Symposium and Intelligent Robotics Meeting, Montreal, QC, Canada, 3-5 October 2010; pp. 7-12.

92. Workman, K.; Elzer, S. Utilizing Microsoft robotics studio in undergraduate robotics. J. Comput. Sci. Coll. 2009, $24,65-71$.

93. Kanehiro, F.; Hirukawa, H.; Kajita, S. Openhrp: Open architecture humanoid robotics platform. Int. J. Robot. Res. 2004, 23, 155-165. [CrossRef]

94. Cisneros, R.; Yoshida, E.; Yokoi, K. Ball dynamics simulation on openhrp3. In Proceedings of the 2012 IEEE International Conference on Robotics and Biomimetics (ROBIO), Guangzhou, China, 11-14 December 2012; pp. 871-877.

95. Michel, O. Khepera Simulator Version 2.0, User Manual. Université de Nice-Sophia Antipolis; Laboratoire I3S-CNRS, France/EPFL-Lausanne, Swiss: Valbonne, France, 1996.

96. McDowell, P.; Darken, R.; Sullivan, J.; Johnson, E. Delta3D: A complete open source game and simulation engine for building military training systems. J. Def. Model. Simul. 2006, 3, 143-154. [CrossRef]

97. Darken, R.; McDowell, P.; Johnson, E. Projects in VR: The Delta3D open source game engine. IEEE Comput. Graph. Appl. 2005, 25, 10-12. [CrossRef]

98. Corke, P.I. A robotics toolbox for MATLAB. IEEE Robot. Autom. Mag. 1996, 3, 24-32. [CrossRef] 
99. Corke, P.I. A computer tool for simulation and analysis: The Robotics Toolbox for MATLAB. In Proceedings of the Australian Conference on Robotics Association, Brisbane, Australia, 5-7 July 1995; pp. 319-330.

100. Toz, M.; Kucuk, S. Dynamics simulation toolbox for industrial robot manipulators. Comput. Appl. Eng. Educ. 2010, 18, 319-330. [CrossRef]

101. Karakaya, S.; Kucukyildiz, G.; Ocak, H. A new mobile robot toolbox for MATLAB. J. Intell. Robot. Syst. 2017, 87, 125-140. [CrossRef]

102. Mondada, F.; Pettinaro, G.C.; Guignard, A.; Kwee, I.W.; Floreano, D.; Deneubourg, J.L.; Nolfi, S.; Gambardella, L.M.; Dorigo, M. SWARM-BOT: A new distributed robotic concept. Auton. Robot. 2004, 17, 193-221. [CrossRef]

103. Pettinaro, G.C.; Kwee, I.W.; Gambardella, L.M. Definition, Implementation, and Calibration of the Swarmbot3d Simulator; Technical Report No. IDSIA-21-03; IDSIA: Manno, Switzerland, 2003.

104. Pettinaro, G.C.; Kwee, I.W.; Gambardella, L.M. Swarmbot3D User Manual. 2003. Available online: https://repository.supsi.ch/ 5558/1/IDSIA-22-03.pdf (accessed on 11 June 2021).

105. Dabek, P.; Trojnacki, M.; Jaroszek, P.; Zawieska, K. Concept, Physical Design and Simulator of IRYS Social Robot Head In Proceedings of the International Conference Mechatronics, Brno, Czech Republic, 6-8 September 2017; pp. 91-100.

106. Costa, H.; Tavares, P.; Santos, J.; Rio, V.; Sousa, A. Simulation of a System Architecture for Cooperative Robotic Cleaning. In Proceedings of the Robot 2015: Second Iberian Robotics Conference, Lisbon, Portugal, 19-21 November 2015; pp. 717-728.

107. Couceiro, M.S.; Araújo, A.G.; Tatarian, K.; Ferreira, N.M. RobotCraft: The first international collective internship for advanced robotics training. In International Conference on Robotics and Education RiE 2017; Springer: Cham, Switzerland, 2018 ; pp. 31-43.

108. Conte, G.; Scaradozzi, D.; Mannocchi, D.; Raspa, P.; Panebianco, L.; Screpanti, L. Development and experimental tests of a ROS multi-agent structure for autonomous surface vehicles. J. Intell. Robot. Syst. 2018, 92, 705-718. [CrossRef]

109. Araújo, A.; Portugal, D.; Couceiro, M.S.; Rocha, R.P. Integrating Arduino-based educational mobile robots in ROS. J. Intell. Robot. Syst. 2015, 77, 281-298. [CrossRef]

110. Tatarian, K.; Pereira, S.; Couceiro, M.S.; Portugal, D. Tailoring a ROS educational programming language architecture. In International Conference on Robotics and Education RiE; Springer: Cham, Switzerland, 2018; pp. 217-229.

111. Koubâa, A. (Ed.). Robot Operating System (ROS); Springer: Berlin/Heidelberg, Germany, 2017; Volume 1, pp. 112-156.

112. Quigley, M.; Gerkey, B.; Smart, W.D. Programming Robots with ROS: A Practical Introduction to the Robot Operating System; O'Reilly Media, Inc.: Sebastopol, CA, USA, 2015. 